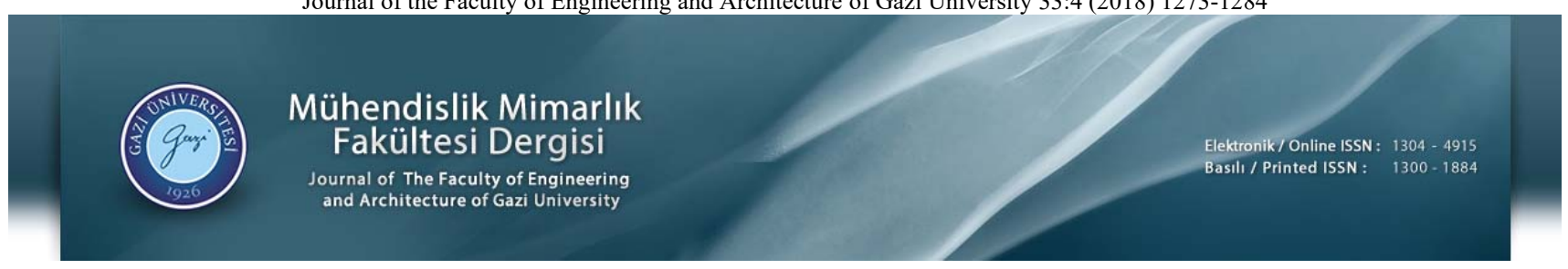

\title{
$3 \mathrm{DOM} \mathrm{CeO}_{2}$ and $3 \mathrm{DOM} \mathrm{ZrO}_{2}$ supported nickel catalysts: synthesis, characterization and catalytic activity studies
}

\section{Filiz Balıkçı Derekaya(D), İkbal Ay (D)}

Department of Advanced Technologies, Graduate School Of Natural And Applied Sciences, Gazi University, Ankara, 06500, Turkey

\section{Highlights:}

- The $\mathrm{CeO}_{2}$ and $\mathrm{ZrO}_{2}$ were obtained in 3DOM structures of which pore diameters change in between 204-321 nm

- Th mesopores were obtained within the macropore walls

- The $18.6 \% \mathrm{NH}_{3}$ conversions was observed over $\mathrm{NiO} / 3 \mathrm{DOM} \mathrm{CeO}_{2}$ catalysts at $600^{\circ} \mathrm{C}$

\section{Keywords:}

- 3DOM

- catalysts

- ammonia

- hydrogen

- polystyrene

\section{Article Info:}

Received: 24.02.17

Accepted: 11.08.17

\section{DOI:}

10.17341/gazimmfd.416424

\section{Acknowledgement:}

18/2014-01

Dilek Varışlı

\section{Correspondence:}

Author:Filiz Balıç̧ı

Derekaya

e-mail: filizb@gazi.edu.tr phone: +90312 5824519

\section{Graphical/Tabular Abstract}

The $3 \mathrm{DOM} \mathrm{ZrO}_{2}$ and $3 \mathrm{DOM} \mathrm{CeO}_{2}$ supported nickel composed catalysts were synthesizd, characterized and tested for the hydrogen production from ammonia. Characterization results indicates that $\mathrm{CeO}_{2}$ and $\mathrm{ZrO}_{2}$ were obtained in three dimensionally ordered macroporous structures of which pore diameters change in between 204-321 nm. SEM results also showed that $\mathrm{NiO}$ was successfully impregranted in to the $3 \mathrm{DOM}$ pore structures. The desired crystal phases were obtained over the catalysts and supports. All supports and catalysts have mesopores besides macropores. The catalytic activity studies were performed in order to obtain hydrogen recovery from ammonia between the temperatures of $400-600^{\circ} \mathrm{C}$. The catalytic activity of up to $500^{\circ} \mathrm{C}$ was low enough to be ignored. Elevation of the reaction temperature increases the conversion. At $600^{\circ} \mathrm{C}$ temperature, $5.6 \%$ and $18.6 \% \mathrm{NH}_{3}$ conversions were observed over the $\mathrm{NiO} / 3 \mathrm{DOM} \mathrm{ZrO}_{2}$ and $\mathrm{NiO} / 3 \mathrm{DOM} \mathrm{CeO} 2$ catalysts, respectively.

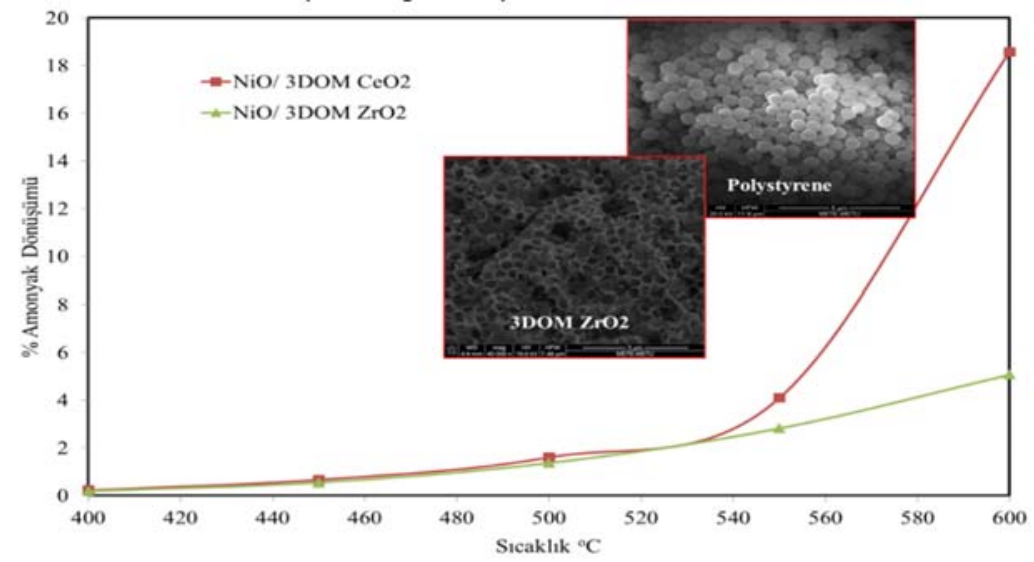

Figure A. Catalytic activities of the $3 \mathrm{DOM} \mathrm{CeO}_{2}$ and $3 \mathrm{DOM} \mathrm{ZrO}_{2}$ supported $\mathrm{Ni}$ Catalysts

Purpose: The aim of this study is to prepare $\mathrm{NiO}$ composed $3 \mathrm{DOM} \mathrm{CeO}_{2}$ and $3 \mathrm{DOM} \mathrm{ZrO}_{2}$ supported catalysts.

\section{Theory and Methods:}

The 3DOM supports were synthesized by the colloidal crystal templating method by using the polystyrene (PS) as template and then nickel was incorporated in to the 3DOM structure by the gas bubbling assisted deposition precipitation method. All materials were characterized by using the following characterization techniques: $\mathrm{N}_{2}$ phsisorption, X-Ray diffraction, scanning electron microscopy (SEM-EDX).

Results:

Characterization results indicates that $\mathrm{CeO}_{2}$ and $\mathrm{ZrO}_{2}$ were obtained in three dimensionally ordered macroporous structures of which pore diameters change in between 204-321 nm. SEM results also showed that $\mathrm{NiO}$ was successfully impregnated in to the $3 \mathrm{DOM}$ pore structures.

Conclusion:

The $\mathrm{NiO} / 3 \mathrm{DOM} \mathrm{CeO}_{2}$ and $\mathrm{NiO} / 3 \mathrm{DOM} \mathrm{ZrO}_{2}$ catalysts were successfully prepared by using the colloidal crystal templating method. All catalysts composed mesopores besides macropores. 


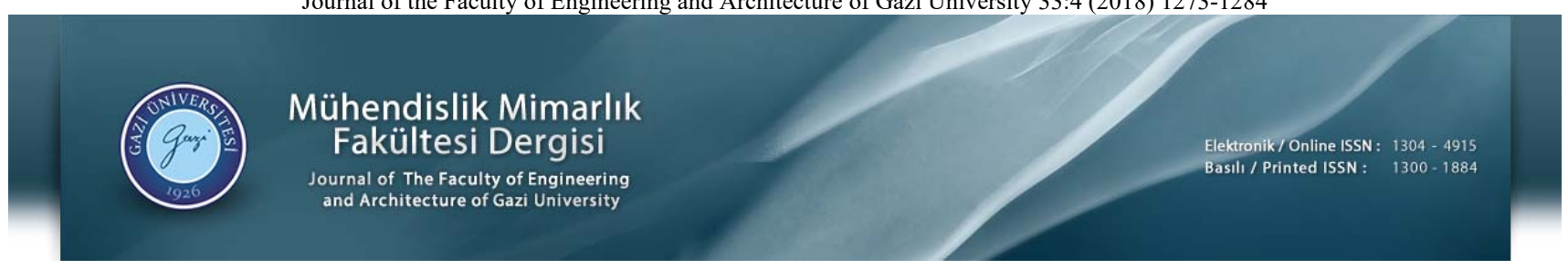

\section{$3 \mathrm{DOM} \mathrm{CeO}_{2}$ ve $3 \mathrm{DOM} \mathrm{ZrO}_{2}$ destekli nikel katalizörlerin sentezi, karakterizasyonu ve katalitik aktivite çalışmaları}

Filiz Balıkçı Derekaya*(iD, İkbal Ay (iD)

Gazi Üniversitesi, Fen Bilimleri Enstitüsü, İleri Teknolojiler Anabilim dalı, 06500, Ankara, Türkiye

Ö N E Ç I K A N L A R

- $\quad 3 \mathrm{DOM} \mathrm{CeO}_{2}$ ve 3DOM $\mathrm{ZrO}_{2}$ gözenek çapları 204-321 nm arasında elde edildiler

- Makrogözenek duvarları içinde mezogöenekler elde edildi

- $\quad \mathrm{NiO} / 3 \mathrm{DOM} \mathrm{CeO}_{2}$ katalizöründen $600^{\circ} \mathrm{C}$ sıcaklığında $\% 18,6 \mathrm{NH}_{3}$ dönüşümü elde edildi

Makale Bilgileri

Geliş: 24.02.2017

Kabul: 11.08.2017

DOI:

$10.17341 /$ gazimmfd.416424

Anahtar Kelimeler:

3DOM,

katalizörler,

amonyak,

hidrojen

\section{ÖZET}

Bu çalışmada $3 \mathrm{DOM} \mathrm{ZrO}_{2}$ ve $3 \mathrm{DOM} \mathrm{CeO}_{2}$ destekli nikel içeren katalizörlerin sentezi, karakterizyonu ve amonyaktan hidrojen üretim reaksiyonu için aktivite çalışmaları gerçekleştirilmiştir. 3DOM destekler polistiren (PS)'in şablon olarak kullanıldı ğı kolloidal kristal şablonlama metodu kullanılarak hazırlanmış ve daha sonra nikel destek yapısına gaz kabarcığı yardımı ile çökelti (tortu) birikimi yöntemi ile katılmıştır. Tüm malzemeler $\mathrm{N}_{2}$ fizisorpsiyon, taramalı elektron mikroskobu (SEM-EDX) ve X-1şını kırınım deseni analizi çalışmaları ile karakterize edilmişlerdir. SEM sonuçları $\mathrm{CeO}_{2}$ ve $\mathrm{ZrO}_{2}$ desteklerinin üç boyutlu düzenli makrogözenekli yapıda sentezlendiğini ve gözenek çaplarının 204-321 nm arasında değiştiğini göstermiştir. SEM sonuçları aynı zamanda NiO'in 3DOM gözenek yapısı içine başarılı bir şekilde girdiğini de göstermiştir. Destek ve katalizörlerin yapısında makrogözeneklerin yanında mezogözeneklerinde olduğu belirlenmiştir. Amonyaktan hidrojen üretim reaksiyonu $400-600^{\circ} \mathrm{C}$ sıcaklıkları arasında gerçekleştirilmiştir. $500^{\circ} \mathrm{C}$ 'ye kadar katalizörler ihmal edilebilir katalitik aktivite göstermişlerdir. Reaksiyon sıcaklığının yükselmesi ile aktivitelerde yükselmiştir. $600^{\circ} \mathrm{C}$ sicaklıkta $\mathrm{NiO} / 3 \mathrm{DOM} \mathrm{ZrO}_{2}$ and $\mathrm{NiO} / 3 \mathrm{DOM} \mathrm{CeO}_{2}$ katalizörlerinden sırasıyla \%5,6 ve \%18,6 $\mathrm{NH}_{3}$ dönüşümü elde edilmiştir.

\section{$3 \mathrm{DOM} \mathrm{CeO}_{2}$ and $3 \mathrm{DOM} \mathrm{ZrO}_{2}$ supported nickel catalysts: synthesis, characterization and catalytic activity studies}

\section{H I G H L I G H T S}

- $\quad$ The $\mathrm{CeO}_{2}$ and $\mathrm{ZrO}_{2}$ were obtained in 3DOM structures of which pore diameters change in between 204-321 nm

- Th mesopores were obtained within the macropore walls

- $\quad$ The $18.6 \% \mathrm{NH}_{3}$ conversions was observed over $\mathrm{NiO} / 3 \mathrm{DOM} \mathrm{CeO}_{2}$ catalysts at $600^{\circ} \mathrm{C}$

Article Info

Received: 24.02.2017

Accepted: 11.08 .2017

DOI:

10.17341/gazimmfd.416424

Keywords:

3DOM,

catalysts,

ammonia,

hydrogen

\section{ABSTRACT}

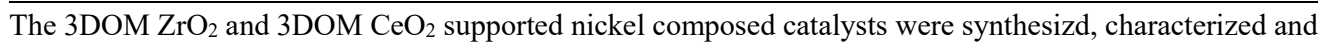
tested for the hydrogen production from ammonia. The 3DOM supports were synthesized by the colloidal crystal templating method by using the polystyrene (PS) as template and than nickel was incorporated in to the 3DOM structure by the gas bubbling assisted deposition precipitation method. All materials were characterized by using the following characterization techniques: $\mathrm{N}_{2}$ phsisorption, X-Ray diffraction, scanning electron microscopy (SEM-EDX). SEM results indicates that $\mathrm{CeO}_{2}$ and $\mathrm{ZrO}_{2}$ were obtained in three dimensionally ordered macroporous structures of which pore diameters change in between 204-321 nm. SEM results also showed that $\mathrm{NiO}$ was successfully impregnated in to the $3 \mathrm{DOM}$ pore structures. The desired crystal phases were obtained over the catalysts and supports. All supports and catalysts have mesopores besides macropores. The catalytic activity studies were performed in order to obtain hydrogen recovery from ammonia between the temperatures of $400-600^{\circ} \mathrm{C}$. The catalytic activity of up to $500^{\circ} \mathrm{C}$ was low enough to be ignored. Elevation of the reaction temperature increases the conversion. At $600^{\circ} \mathrm{C}$ temperature, $5.6 \%$ and $18.6 \% \mathrm{NH}_{3}$ conversions were observed over the $\mathrm{NiO} / 3 \mathrm{DOM} \mathrm{ZrO}_{2}$ and $\mathrm{NiO} / 3 \mathrm{DOM}$ $\mathrm{CeO}_{2}$ catalysts, respectively.

\footnotetext{
*Sorumlu Yazar/Corresponding Author: filizb@gazi.edu.tr / Tel: +90312 5824519 


\section{GIRISŞ (INTRODUCTION)}

Gözenekli malzemeler arasında üç boyutlu düzenli makrogözenekli (3DOM) malzemeler önemli bir sınıftır. 3DOM malzemelerin katalizörler açısından önemi bu malzemelerin tek tip düzenli yapılarından, içten bağlı makrogözeneklerine aktif bileşenlerin yerleşebilmesinden ve mezo gözeneklerinin yüksek yüzey alanı sağlamasından kaynaklanmaktadır. Tek tip gözenekliliğe sahip (>50 nm) üç boyutlu düzenli makrogözenekli (3DOM) metal oksitler heterojen katalizör sınıflandırmasında çok dikkat çekmektedir. Çünkü bu malzemelerin makrogözenekli yapıları iç duvarlar üzerine girilebilir siteler sağlamaktadır. Soy metal nanopartikülleri ile 3DOM metal oksitlerin katalitik aktivitesi geliştirilebilmektedir [1, 2]. Literatürde yer alan çalışmalar incelenerek 3DOM destekli katalizörlerin kullanıldıkları reaksiyonlar belirlenmiştir. Liu vd. [2] ark. 3DOM destekleri hidrojence zengin gaz karışımından CO' in seçimli oksidasyonu reaksiyonunda; Xu vd. [3] ile Wei vdç [4] dizel motorlarının egzoz gazındaki zararlı bileşenlerin yok edilmesinde; Han vd. [5] hidrodesülfirizasyon prosesinde; Zhang vd. [6] formaldehit oksidasyonunda; Ji vd. [7] toluen yanmasında ve Zhang vd. [8] Fischer Tropsch sentezinde kullanmışlardır. Günümüze birçok 3DOM yapıda olan malzeme polimer mikrokürelerin şablon olarak kullanıldığı kolloidal kristal şablonlama tekniği (CCT) ile başarılı bir şekilde hazırlanmaktadır [5]. Kolloidal kristal şablonlama (colloidal crystal templating method (CCT)) metodu makrogözenekli malzemeleri özellikle 3DOM yapıda hazırlamak için çok etkili bir metoddur [5]. Kolloidal kristal şablonlama metodunun temelinde, polistiren (polystyrene PSTY), polimetilmetakrilat (polymethylmethacrylate (PMMA)) ya da silika gibi düzenli monodispers küreler bulunmaktadır. Düzenli küreler arasındaki çatlaklar akışkan formdaki başlangıç maddesi ile doldurulmaktadır. Bu akışkan başlangıç maddesi çatlaklara nüfuz ederek ara bileşik yapı oluşturarak kuvvetlendirme yapmaktadır. Şablon küreler kalsinasyon ya da ekstraksiyon ile yapıdan çıkarılmakta ve katı iskelet yapı elde edilmekte ve geriye kürelerden hava boşlukları kalmaktadır [5].

Hidrojen gelecek enerji sistemleri için önemli temiz enerji kaynağıdır. Hidrojenin üretilebileceği bir reaksiyonda $\mathrm{NH}_{3}$ 'ın bozulma reaksiyonudur. Amonyağın bozulma reaksiyonu ile karbon içermeyen $\mathrm{H}_{2}$ üretilebilmektedir. Amonyağın bozulma reaksiyonu Fe, Ni, Pt, Ru, Co, Ir, Pd ve Rh metallerini içeren katalizörler ile oldukça çalışılmıştır. Zhang vd. [9] $\mathrm{NH}_{3}$ bozunması ile $\mathrm{H}_{2}$ üretimini Co/MWCNT ler üzerinden incelemişler. Yao vd. [10] $\mathrm{NH}_{3}$ bozunmasından $\mathrm{H}_{2}$ üretimi için $\mathrm{SiO}_{2}, \mathrm{Al}_{2} \mathrm{O}_{3}$ ve $\mathrm{MgO}$ destekli Fe, $\mathrm{Co}$, Ni ve $\mathrm{Ru}$ içeren katalizörler hazırlamışlar. Lorenzut vd. [11] FeMo içeren katalizörler üzerinden $\mathrm{NH}_{3}$ ' dan $\mathrm{H}_{2}$ üretimini incelemişler. Nakamura vd. [12] nikel katalizörlerde metaloksit desteğin $\mathrm{NH}_{3}$, den $\mathrm{H}_{2}$ üretimine etkisini incelemişler. Ru-temelli katalizörler amonyağın bozunma reaksiyonu için en aktif katalizörler olarak belirlenmiştir. Amonyağın bozulma reaksiyonu için çalışılan katalizörlerin çoğu mezogözenekli yapıdadır. Literatürde yer alan çalışmalar açıkça göstermiştirki makrogözenekler içeren katalizörler bu reaksiyon için test edilmemişlerdir. $\mathrm{Bu}$ çalışmanın amacı nikeloksit içeren 3DOM $\mathrm{ZrO}_{2}$ ve $3 \mathrm{DOM}$ $\mathrm{CeO}_{2}$ destekli katalizörlerin hazırlanmasıdır. $\mathrm{Bu}$ amaçla 3DOM destekler kolloidal kristal şablonlama tekniği ile hazırlanmış ve yapıya nikel gaz kabarcığı yardımı ile çökelti (tortu) birikimi yöntemi ile katılmıştır. Hazırlanan tüm malzemeler karakterize edilmiş ve amonyaktan hidrojen üretim reaksiyonu için test edilmişlerdir.

\section{DENEYSEL METOD (EXPERIMENTAL METHOD)}

\subsection{Katalizör Hazırlanması (Catalyst Preparation)}

$3 \mathrm{DOM} \mathrm{CeO} 2$ ve $3 \mathrm{DOM} \mathrm{ZrO}_{2}$ destekleri kullanılarak 50/50 mol. \% NiO/3DOM CeO 2 ve 50/50 mol. \% NiO/3DOM $\mathrm{ZrO}_{2}$ katalizörleri hazırlanmıştır. Destek malzemelerin ve katalizörlerin hazırlanması için Liu vd. [13] tarafından verilen yöntem takip edilmiştir. Bu yöntem 4 aşamadan oluşmaktadır: (1) Monodispers polisitrien (PS) kürelerin hazırlanması, 2) Üç boyutlu düzenli PS kolloidal kristal şablonların toparlanıp birleştirilmesi, (3) $3 \mathrm{DOM} \mathrm{CeO}_{2}$ ya da $3 \mathrm{DOM} \mathrm{ZrO}_{2}$ 'in sentezi ve (4) $\mathrm{NiO} / 3 \mathrm{DOM} \mathrm{CeO}_{2}$ ya da $\mathrm{NiO} / 3 \mathrm{DOM} \mathrm{ZrO}_{2}$ katalizörlerinin hazırlanması. Üçüncü aşamada $3 \mathrm{DOM} \quad \mathrm{CeO}_{2}$ ya da $3 \mathrm{DOM} \quad \mathrm{ZrO}_{2}$ 'in sentezlenmesinde metal tuzu başlangıç maddeleri olarak $\mathrm{Ce}\left(\mathrm{NO}_{3}\right)_{3} \cdot 6 \mathrm{H}_{2} \mathrm{O}$ (Sigma \%99) ve $\mathrm{Zr}\left(\mathrm{NO}_{3}\right)_{2} \cdot \mathrm{H}_{2} \mathrm{O}$ (Sigma \%99) kullanılmıştır. (3DOM $\mathrm{CeO}_{2}$ ve $3 \mathrm{DOM} \quad \mathrm{ZrO}_{2}$ hazırlamak için $2,17 \mathrm{~g} \mathrm{Ce}\left(\mathrm{NO}_{3}\right)_{3} \cdot 6 \mathrm{H}_{2} \mathrm{O}$ ve $2,17 \mathrm{gr}$ $\mathrm{Zr}\left(\mathrm{NO}_{3}\right) \cdot 2 \mathrm{H}_{2} \mathrm{O}$ başlangıç tuzları 1,05 gr sitrik asit ve $10 \mathrm{ml}$ etanol ile karıştırılmış ve PS kürelerinin üzerinden geçirilmiştir. $\mathrm{Bu}$ işlem 4 defa tekrarlanmıştır). Sitrik asit burada şelat olarak kullanılmış ve monodispers PS kürelerin etrafinda metaloksit halkasal yapıların oluşmasını sağlamıştır.

En son aşamada $\mathrm{CeO}_{2}$ ve $\mathrm{ZrO}_{2}$ kristal faz yapısını elde edebilmek için $3^{\circ} \mathrm{C} /$ dakika isıtma hızında oda sıcaklığından $500^{\circ} \mathrm{C}^{\prime}$ ye 1sitılarak bu sicaklikta 3 saat boyunca 1 sıl işlem uygulanmıştır. Dördüncü aşamada NiO'in yapıya eklenmesi için metal tuzu başlangıç maddesi olarak Ni( $\left.\mathrm{NO}_{3}\right)_{2} \cdot 6 \mathrm{H}_{2} \mathrm{O}$ (Sigma \%99) kullanıllmıştır. (1 gr 50/50 mol.\% $\mathrm{NiO} / 3 \mathrm{DOMX}$ katalizörünü hazırlamak için kullanılan miktarlar: $\mathrm{NiO} / 3 \mathrm{DOMCeO}_{2}$ ve $\mathrm{NiO} / 3 \mathrm{DOM} \quad \mathrm{ZrO}_{2}$ katalizörleri için sırasıyla $0,85 \mathrm{gr} 3 \mathrm{DOM} \mathrm{CeO}_{2}+1,498$ gr $\mathrm{Ni}\left(\mathrm{NO}_{3}\right)_{2} \cdot 6 \mathrm{H}_{2} \mathrm{O}$ ve 0,804 gr $3 \mathrm{DOM} \mathrm{ZrO}_{2}+1,958$ gr $\left.\mathrm{Ni}\left(\mathrm{NO}_{3}\right)_{2} \cdot 6 \mathrm{H}_{2} \mathrm{O}\right)$. Son olarak $\mathrm{NiO}$ kristal faz yapisinı elde edebilmek için $3^{\circ} \mathrm{C} /$ dakika isıtma hızında oda sıcaklığından $500^{\circ} \mathrm{C}^{\prime}$ ye 1 sitılarak bu sicaklıkta 3 saat boyunca 1 sıl işlem uygulanmıştır.

\subsection{Katalizör Karakterizasyonu (Catalysts Characterization)}

Katalizörlerin fiziksel özelliklerini belirlemek için farklı teknikler kullanılmıştır. Bu teknikler: X-Işını kırınım deseni analizi (XRD), $\mathrm{N}_{2}$ fizisorpsiyonu, taramalı elektron mikroskopisi (SEM). Katalizörlerin çok noktalı yüzey alanı (BET), gözenek hacimleri ve gözenek çapları Quantochrome 
Autosorp 1C/MS cihazı kullanılarak belirlenmiştir. Bu cihazda ölçümlere başlamadan önce tüm örneklere $300^{\circ} \mathrm{C}$ 'de 1 saat boyunca degas işlemi uygulanmıştır. Bu uygulama ile katalizör yapısında bulunan su uzaklaştırılmış ve gözeneklerin boşaltılması sağlanmıştır. Ortalama gözenek çapı BJH metodu kullanılarak belirlenmiştir. Katalizörlerin X-Işını kırınım desenleri PHILIS PW 1840 difraktometresi kullanılarak elde edilmiştir. XRD desenlerinin eldesinde $\mathrm{CuK} \alpha$ radyasyanu üreten Rigaku dönen anotlu X-1şını difraktometre sistemi kullanılmıştır. Yüzey morfolojisi ve bileşenlerin yüzeyde dağılım oranları taramalı elektron mikroskopisi (SEM-EDX) analizinden elde edilmiştir. SEM görüntüleri ve EDX analizleri "XT microscope control" programını kullanan NOVA NANOSEM 430 cihazında gerçekleştirilmiştir.

\subsection{Aktivite Çalışmaları (Activity Studies)}

3DOM desteklerin, 50/50 mol. \% $\mathrm{NiO} / 3 \mathrm{DOM} \mathrm{CeO}_{2}$ ve 50/50 mol. \% NiO/ 3DOM $\mathrm{ZrO}_{2}$ katalizörlerinin katalitik aktiviteleri amonyaktan hidrojen üretim reaksiyonu için incelenmiştir. Katalitik aktivite testlerinde katalizörün cam yünü ile desteklendiği ve reaktör boyunca gaz karışımının akış hızının sabit kaldığ 1 diferansiyel reaktör sistemi kullanılmıştır. İç çap1 $1 / 4$ inç olan paslanmaz çelik boru reaktör içine $0,05 \mathrm{~g}$ katalizör yerleştirilmiş ve iki taraftan quvartz cam yünü ile desteklenmiştir. Reaktör daha sonra aktivite testlerinin yapılacağı borusal firına yerleştirilmiştir. Aktivite testleri $400-600^{\circ} \mathrm{C}$ sicaklıkları arasında gerçekleştirilmiştir. Oda sicaklığında saf amonyak gazı sisteme $50 \mathrm{ml} /$ dakika akış hızında beslenmiştir. Aktivite testlerinden önce katalizör $500^{\circ} \mathrm{C}$ 'de 1 saat boyunca saf hidrojen gazı altında indirgenmiştir. Reaksiyona giren bileşenlerin ve reaksiyon ürünlerinin analizi TCD dedektörlü ve Propak Q kolonlu gaz kromotograf sisteminde belirlenmiştir. Amonyağın hidrojene dönüşüm miktarı aşağıda yer alan Eş. 1 ve Eş. 2'den yararlanılarak hesaplanmıştır. Burada $\mathrm{X}$ : amonyağın hidrojene dönüşüm oranı; $F_{\mathrm{NH}_{3}}^{0}=$ reaksiyon başlamadan beslemede bulunan amonyak miktarı; $F_{\mathrm{NH}_{3}}=$ reaksiyon sonunda dönüşmeden kalan amonyak miktarı; $F_{N_{2}}=$ reaksiyon sonu oluşan azot miktarını göstermektedir.

$$
\begin{aligned}
& X=\frac{F_{N H_{3}}^{0}-F_{N H_{3}}}{F_{N H_{3}}^{0}} \\
& F_{N H_{3}}^{0}=F_{N H_{3}}-2 F_{N_{2}}
\end{aligned}
$$

\section{SONUÇLAR VE TARTIŞMALAR (RESULTS AND DISCUSSIONS)}

\subsection{Karakterizasyon Sonuçları (Characterization Results)}

3.1.1 Taramalı elektron mikroskopisi sonuçları- SEM (Scanning electron microscopy resulst)

Yap1ya $\mathrm{Zr}\left(\mathrm{NO}_{3}\right) \cdot 6 \mathrm{H}_{2} \mathrm{O}$ ve $\mathrm{Ce}\left(\mathrm{NO}_{3}\right) \cdot 6 \mathrm{H}_{2} \mathrm{O}$ eklemeden önce monodispers PS kürelerinin oluşup oluşmadığını gözlemlemek için taramalı elektron mikroskobu ile SEM görüntüleri çekilmiştir. Monodispers PS kürelerinin SEM görüntüleri Şekil 1'de verilmiştir. Monodispers PS kürelerinin düzgün, son derece düzenli bir yapıda ve şekil olarak aynı oluştukları SEM fotoğraflarından görülmektedir. Sonuçlardan kürelerin çapının yaklaşık 591- $713 \mathrm{~nm}$ aralığında değiştiği ve kürelerin ortalama çapının $\approx 623 \mathrm{~nm}$ olduğu belirlenmiştir. Elde edilen monodispers PS küreler literatürde yer alan çalışmalarla büyük uyum içindedir. Liu vd. [14] ve Zhang vd. [15] çalışmalarında bezner şekil ve boyutta tektip dağılımlı polistiren mikroküreler (PSTY) elde etmişlerdir. Elde edilen monodispers PS kürelerinin 3DOM $\mathrm{CeO}_{2}$ ve $3 \mathrm{DOM} \mathrm{ZrO}_{2}$ desteklerini oluşturmak için şablon

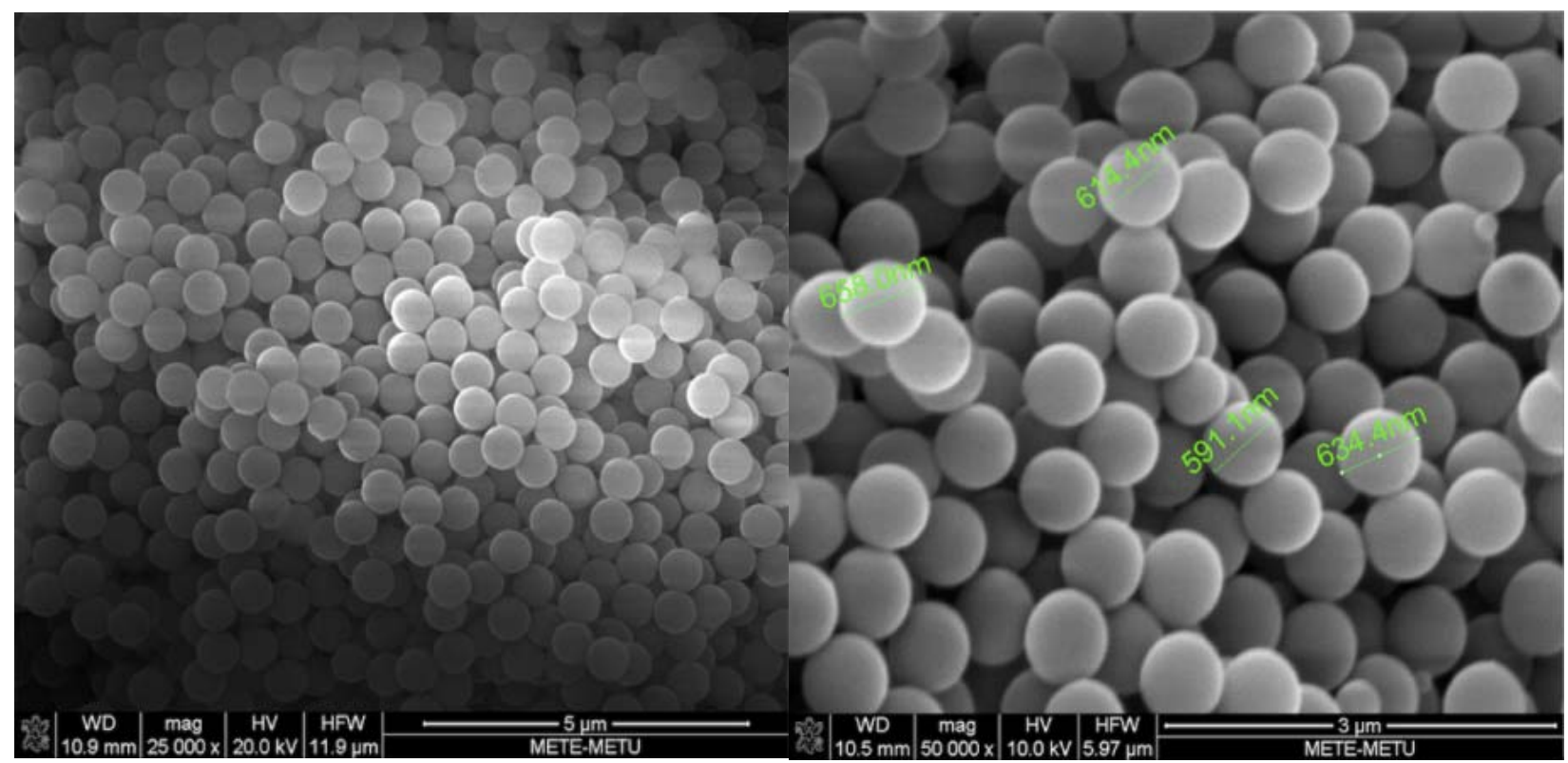

Şekil 1. Tekdağılımlı Polistiren (PSTY) mikrokürelerine ait SEM görüntüleri (SEM images of Monodisperse Polistyrene (PS) microspheres). 
olarak kullanılabileceği SEM görüntüleriyle de tespit edilmiştir. $3 \mathrm{DOM} \mathrm{CeO}_{2}$ ve $3 \mathrm{DOM} \mathrm{ZrO}_{2}$ desteklerine ait SEM görüntüleri Şekil 2'de verilmiştir. Şekil 2'de yapıdaki monodispers polistiren (PSTY) kürelerinin $500^{\circ} \mathrm{C}$ 'de $1 \mathrm{~s} 1 \mathrm{l}$ işlemden sonra uzaklaşmasına bağlı olarak boşlukların (gözeneklerin) oluştuğu görülmektedir. Oluşan gözeneklerin makrogözenek skalasına girdiği ve gözenek çaplarının 204$321 \mathrm{~nm}$ aralığında değiştiği belirlenmiştir. Düzgün bir gözeneklilik elde edildiğini de resimlerden gözlemlemekteyiz. Benzer çalışmalar literatürde de yer almaktadır. Zhang vd. [15] santrifüjleme süresine bağlı olarak 3DOM $\mathrm{CeO}_{2}$ 'i elde etmişler ve $3 \mathrm{DOM} \mathrm{CeO}_{2}$ 'lerin çaplarının da yaklaşık olarak ortalama $240 \mathrm{~nm}$ olduğunu belirtmişlerdir. $\mathrm{Bu}$ çalışmada $3 \mathrm{DOM} \mathrm{CeO}_{2}$ 'in ortalama makrogözenek çap $1 \approx 214 \mathrm{~nm}$ olarak belirlenmiştir. Gözenek boyutlarındaki farklılık hazırlama sırasındaki kurutma ortamı, kurutma sıcaklığı, monomer miktarı, sitrik asit miktarı ve kalsinasyon sıcaklığ 1 , süresi gibi parametere farklılığından kaynaklanmaktadır. Şekil 3'de 3DOM $\mathrm{ZrO}_{2}{ }^{\prime} \mathrm{e}$ ait taramalı elektron mikroskobundan elde edilen SEM görüntüsü verilmiştir. SEM görüntüsünden monodispers polistiren (PSTY) kürelerinin uzaklaşmasından sonra oluşan makrogözeneklerin ortalama çapının $\approx 349 \mathrm{~nm}$ olduğu belirlenmiştir. $\mathrm{Bu}$ çalışmada 3DOM $\mathrm{ZrO}_{2}$ desteği için elde edilen sonuçların Wang vd. [16] ve Li vd. [17] yaptıkları çalışmalardan elde edilen sonuçlara çok yakın olduğu belirlenmiştir.

3DOM $\mathrm{CeO}_{2}$ ve 3DOM $\mathrm{ZrO}_{2}$ desteklerinin yapısina nikeloksit katıldıktan sonra yüzey morfolojisinde gerçekleşen değişimi incelemek amaciyla üretilen katalizörlerin taramalı elektron mikroskobunda resimleri

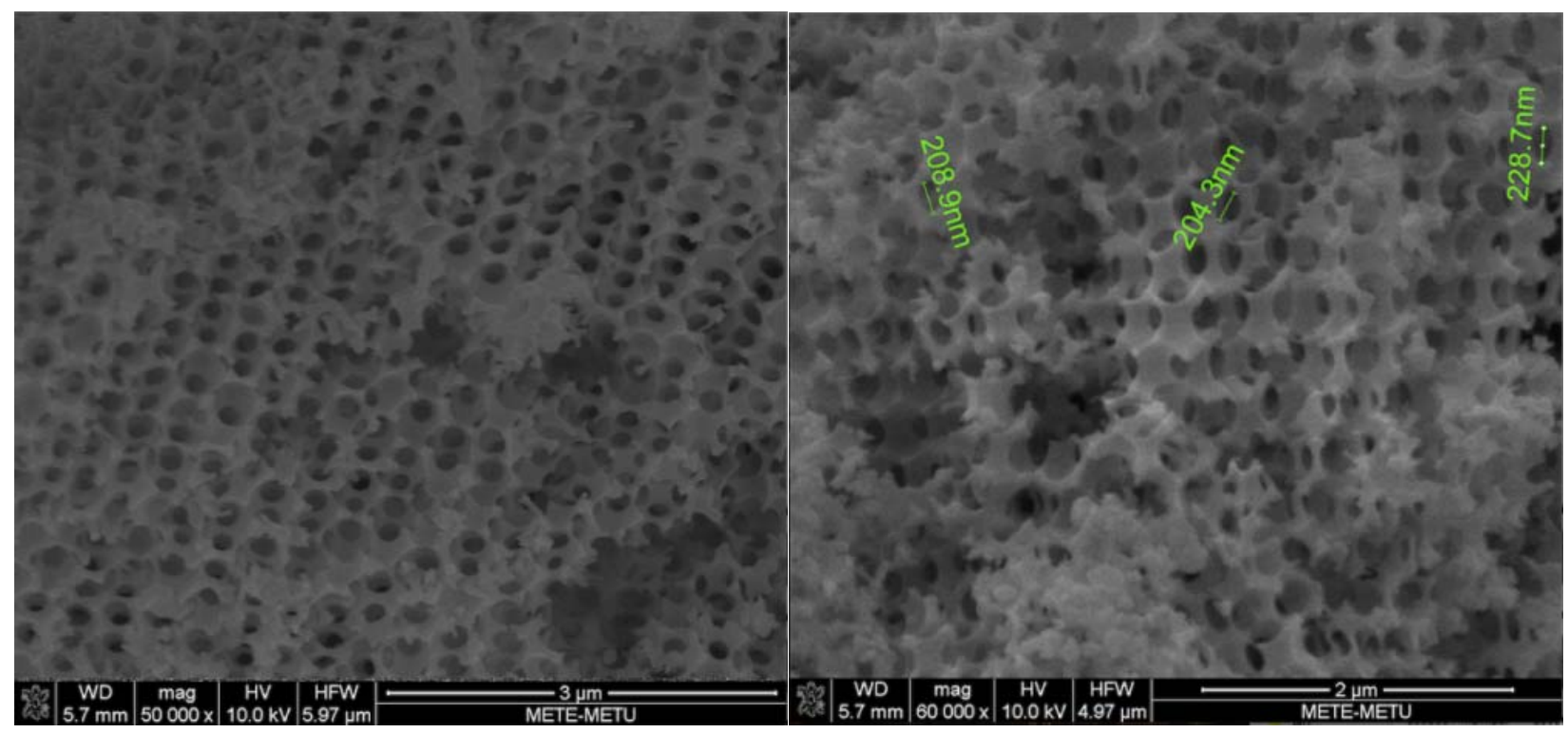

Şekil 2. 3DOM $\mathrm{CeO}_{2}$ desteğine ait $\mathrm{SEM}$ görüntüsü ( $\mathrm{SEM}$ images of $3 \mathrm{DOM} \mathrm{CeO}_{2}$ support)

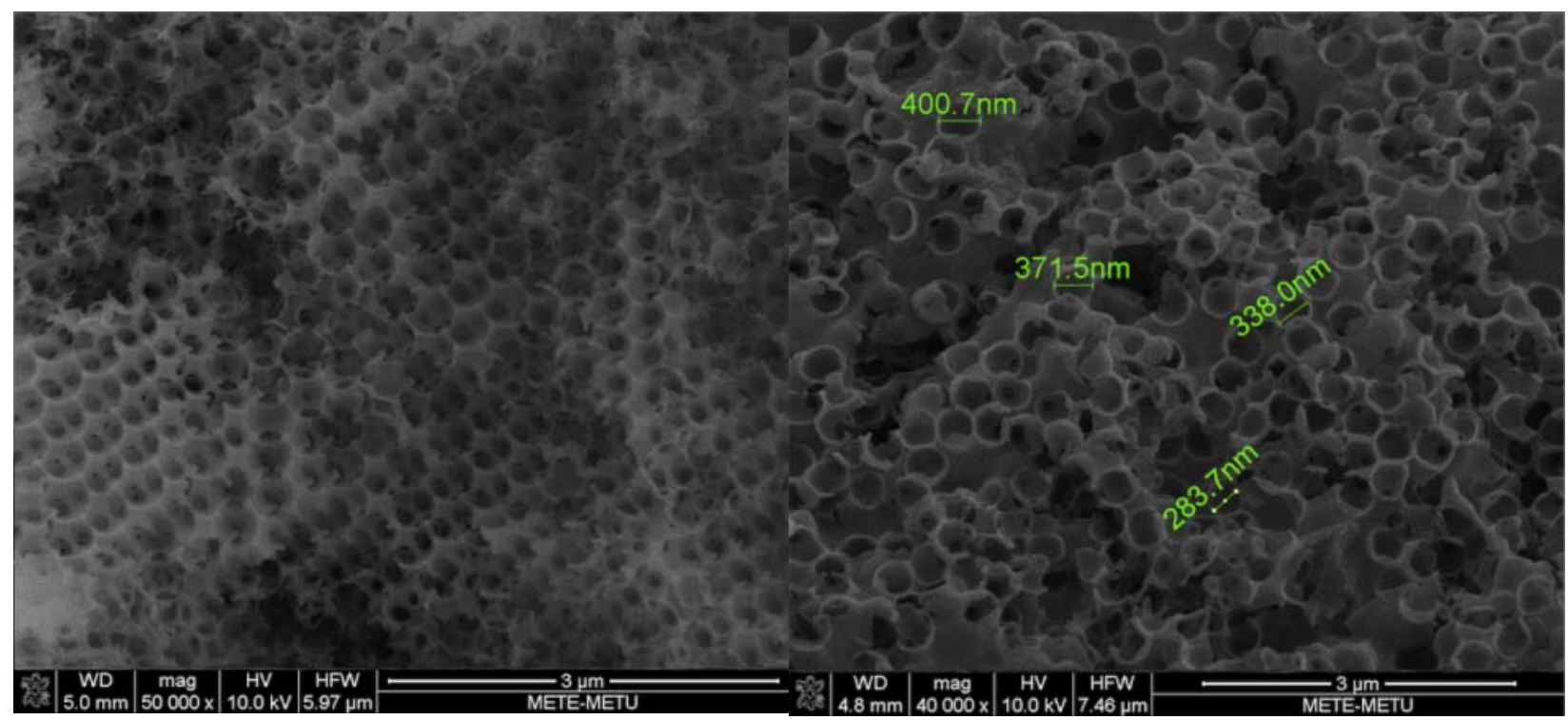

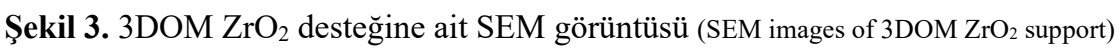


çekilmiştir. Şekil 4'de 3DOM $\mathrm{CeO}_{2}$ yapısına $\mathrm{NiO}$ emdirilerek elde edilen 50/50 mol. \% NiO/ $3 \mathrm{DOM} \mathrm{CeO}_{2}$ ye ait taramalı elektron mikroskobundan elde edilen SEM görüntüsü verilmiştir. 50/50 mol. $\% \mathrm{NiO} / 3 \mathrm{DOM} \mathrm{CeO}_{2}$ katalizörüne ait SEM analiz sonuçlarının 3DOM $\mathrm{CeO}_{2}$ desteğine ait SEM analiz sonucu ile karşılaştırıldığında yuvarlak yapıların kırıldığı, bazı yerlerde yığglmalar olduğu ve gözenek çapının büyüdüğ̈̈ görülmektedir. Bu nedenle $3 \mathrm{DOM} \mathrm{CeO}$ yapısına $\mathrm{NiO}$ 'in emdirildiği düşünülmektedir. $\mathrm{Bu}$ durumda bize 3DOM $\mathrm{CeO}_{2}$ 'in gözenek duvarlarının $\mathrm{NiO}$ ile kaplanmış olabileceğini göstermektedir. SEM fotoğraflarında bazı yerlerde yığılmaların olduğu ve bazı bölgelerde de parlaklıklar olduğu gözlemlenmektedir. $\mathrm{Bu}$ sonuçlarında NiO'den kaynaklandığı düşünülmektedir.

Şekil 5'de 3DOM ZrO 2 yapısına $\mathrm{NiO}$ emdirilerek elde edilen $50 / 50$ mol. \% NiO/ 3DOM $\mathrm{ZrO}_{2}$ 'e ait taramalı elektron mikroskobundan elde edilen SEM görüntüsü verilmiştir. 3DOM $\mathrm{ZrO}_{2}$ 'in SEM görüntüleri ile karşılaştırıldığında $\mathrm{NiO} /$ $3 \mathrm{DOM} \mathrm{ZrO}_{2}$ 'in SEM görüntülerinde yı ğılmalar olduğu ve bu yığılmalarda da parlaklıklar olduğu gözlenmiştir. Bu durumun NiO'ten kaynaklandığı düşünülmektedir. Yapıya $\mathrm{NiO}$ eklenmesiyle birlikte gözenek duvarlarında ve etrafinda kalınlaşmalar olduğu görülmektedir. Duvar kalınlığında olan artış NiO’den kaynaklanmaktadır. Benzer sonuç Liu vd. [2] ve Zhang vd. [2] yaptıkları çalışmalarda da elde edilmiştir. $\mathrm{Au}$ 'ın 3DOM destek yapisında eklenmesinden sonra $\mathrm{Au}$ nanopartiküllerinin biraraya gelip yığılmalar yaptığı ve gözenek çapında da büzülme gerçekleştiği belirlenmiştir. Zhang vd. [8] yaptıkları çalışmada $3 \mathrm{DOM} \mathrm{ZrO}_{2}$ desteğinin yapısına $\mathrm{Co}$ nanopartiküllerinin eklenmesinden sonra yığılmalardan dolayı Co partiküllerinin düzenli dağılım göstermedikleri ve duvar kalınlığında da artış olduğu belirlenmiştir.

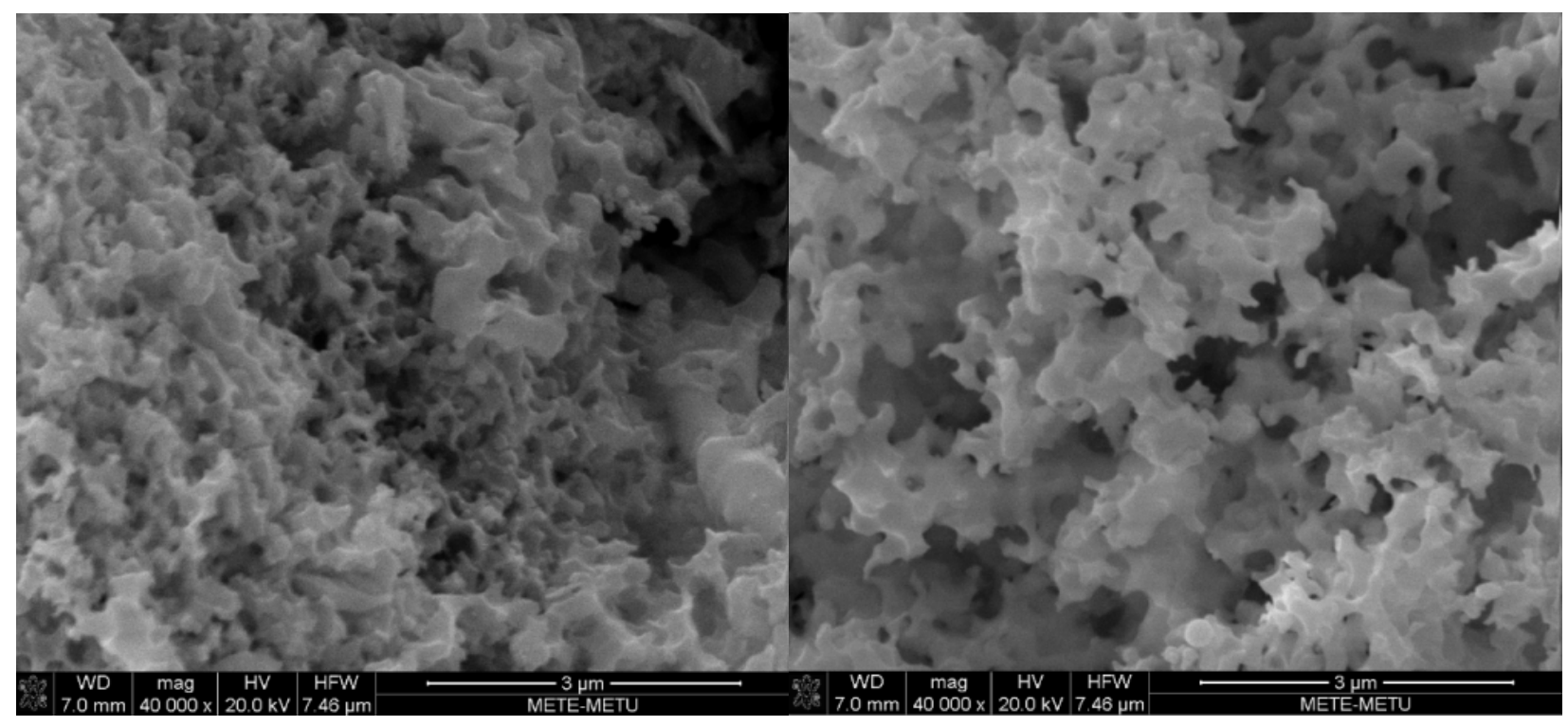

Şekil 4. $\mathrm{NiO} / 3 \mathrm{DOM} \mathrm{CeO}_{2}$ katalizörüne ait $\mathrm{SEM}$ görüntüsü (SEM images of $\mathrm{NiO} / 3 \mathrm{DOM} \mathrm{CeO}_{2}$ catalyst)

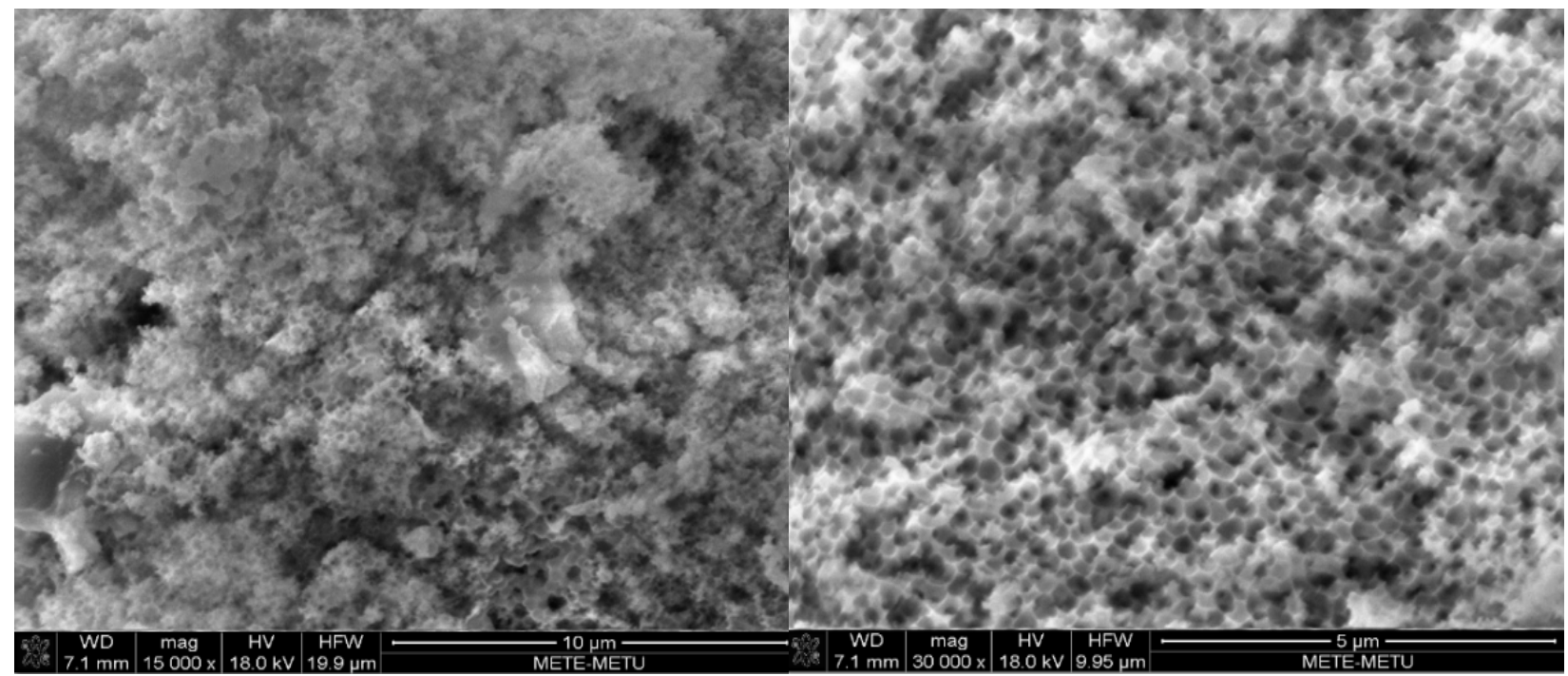

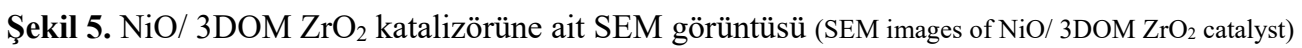


Tablo 1'de SEM-EDX analizinden elde edilen sonuçlar

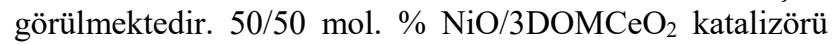
hazırlanırken 3DOM $\mathrm{CeO}_{2}$ katalizör desteğine ait tasarlanan kütlesel oran \%85 iken analiz sonucu kütlesel oran $\% 85,21$ 'dir. NiO'in tasarlanan kütlesel oranı \%15 iken analiz sonucu kütlesel oranı \%14,79'dur. Bu sonuç tasarladığımız oranı elde ettiğimizi göstermektedir. 50/50 mol. \% $\mathrm{NiO} / 3 \mathrm{DOMCeO}_{2}$ katalizörünün molar oranındaki sonuçlara baktığımızda NiO'in tasarlanan molar oran $\% 50$ iken analiz sonucu molar oran $\% 43,26, \mathrm{CeO}_{2}$ 'in tasarlanan mol oran1 $\% 50$ iken analiz sonucu mol oranı \%56,74 olarak elde edilmiştir. Bu sonuç $\mathrm{Ni}\left(\mathrm{NO}_{3}\right)_{2} .6 \mathrm{H}_{2} \mathrm{O}$ metal tuz çözeltisinden oluşan nikel iyonlarının $3 \mathrm{DOM} \mathrm{CeO}_{2}$ desteğin gözeneklerine transferinden kaynaklanmış olabilir. Bir başka ifade ile bir kısım nikel iyonu desteğin gözenekleri içine transfer olmamış olabilir. Sonuç olarak tasarlanan orana çok yaklaşıldığı görülmektedir. Aynı şekilde $\mathrm{NiO} / 3 \mathrm{DOMZrO}_{2}$ katalizöründe de NiO'in tasarlanan kütlesel oranı \%80,4 iken analiz sonucu kütlesel oranı $\% 90,4, \mathrm{ZrO}_{2}$ 'in tasarlanan kütlesel oranı \%19,6 iken analiz sonucu kütlesel oranı \%9,6 olduğu görülmektedir. 50/50 mol. \% NiO/3DOM $\mathrm{ZrO}_{2}$ katalizöründe $\mathrm{NiO}$ 'in tasarlanan mol oranına bakıldığında bu oran $\% 50$ iken analiz sonucu mol oranı \%86,8 olduğu, $\mathrm{ZrO}_{2}$ 'in tasarlanan mol oranı \%50 iken analiz sonucu mol oranı \%13,2 olduğu görülmektedir. Analiz sonucunun daha yüksek çıkmasının sebebi NiO'in 3DOM yapı içerisine tamamen yerleşemeyip bazı bölgelerde yığılma yapmasından kaynaklanmış olabileceği düşünülmektedir.

\subsubsection{X-işını kırınım deseni analiz sonuçları (X-ray diffraction analysis results).}

XRD analizi tasarlanan kristal faz yapısnın oluşup oluşmadığını belirlemek amacıyla kullanılmıştır. Şekil 6'da monodispers polistiren şablonuna ait XRD analiz sonucu ve Şekil 7'de 3DOM desteklerin, NiO/3DOM $\mathrm{CeO}_{2}$ ve $\mathrm{NiO} / 3 \mathrm{DOM} \mathrm{ZrO}_{2}$ katalizörlerine ait XRD analiz sonuçları görülmektedir. Tablo 2'de kristal fazlara ait ortalama kristal boyutları verilmiştir. Polistirende sadece $2 \theta=19,62^{\circ}$ ' de karakteristik pik elde edilmiştir. 3DOM $\mathrm{CeO}_{2}$ ve $3 \mathrm{DOM}$ $\mathrm{ZrO}_{2}$ malzemelerinin X-Işını kırınım deseni analiz sonuçlarında bu açıda herhangi bir pike rastlanılmamıştır (Şekil 7). Bu sonuç bize kalsinasyondan sonra yapıdan monodispers polistiren kürelerinin tamamen uzaklaşmış olduğunu göstermektedir.

Şekil 7'de 3DOM $\mathrm{ZrO}_{2}$ 'in X-Işını kırınım analiz sonuçları görülmektedir. 3DOM $\mathrm{ZrO}_{2}$ 'in $\mathrm{X}$ - 1şını spektrum grafiğinde

Tablo 1. SEM-EDX Analiz Sonuçları (SEM-EDX analysis results)

\begin{tabular}{llllll}
\hline \multirow{2}{*}{ Katalizörlers } & & $\begin{array}{l}\text { Tasarlanan } \\
\text { Kütlesel \% }\end{array}$ & $\begin{array}{l}\text { Kütlesel \% } \\
\text { Analiz Sonucu }\end{array}$ & $\begin{array}{l}\text { Tasarlanan } \\
\text { Molar \% }\end{array}$ & $\begin{array}{l}\text { Molar \% } \\
\text { Analiz Sonucu }\end{array}$ \\
\hline \multirow{2}{*}{$\mathrm{NiO} / 3 \mathrm{DOM} \mathrm{CeO}_{2}$} & $\mathrm{NiO}$ & 15 & 14,8 & 50 & 43,3 \\
& $\mathrm{CeO}_{2}$ & 85 & 85,2 & 50 & 56,7 \\
\hline \multirow{2}{*}{$\mathrm{NiO} / 3 \mathrm{DOM} \mathrm{ZrO}_{2}$} & $\mathrm{NiO}$ & 80,4 & 90,4 & 50 & 86,8 \\
& $\mathrm{ZrO}_{2}$ & 19,6 & 9,6 & 50 & 13,2 \\
\hline
\end{tabular}

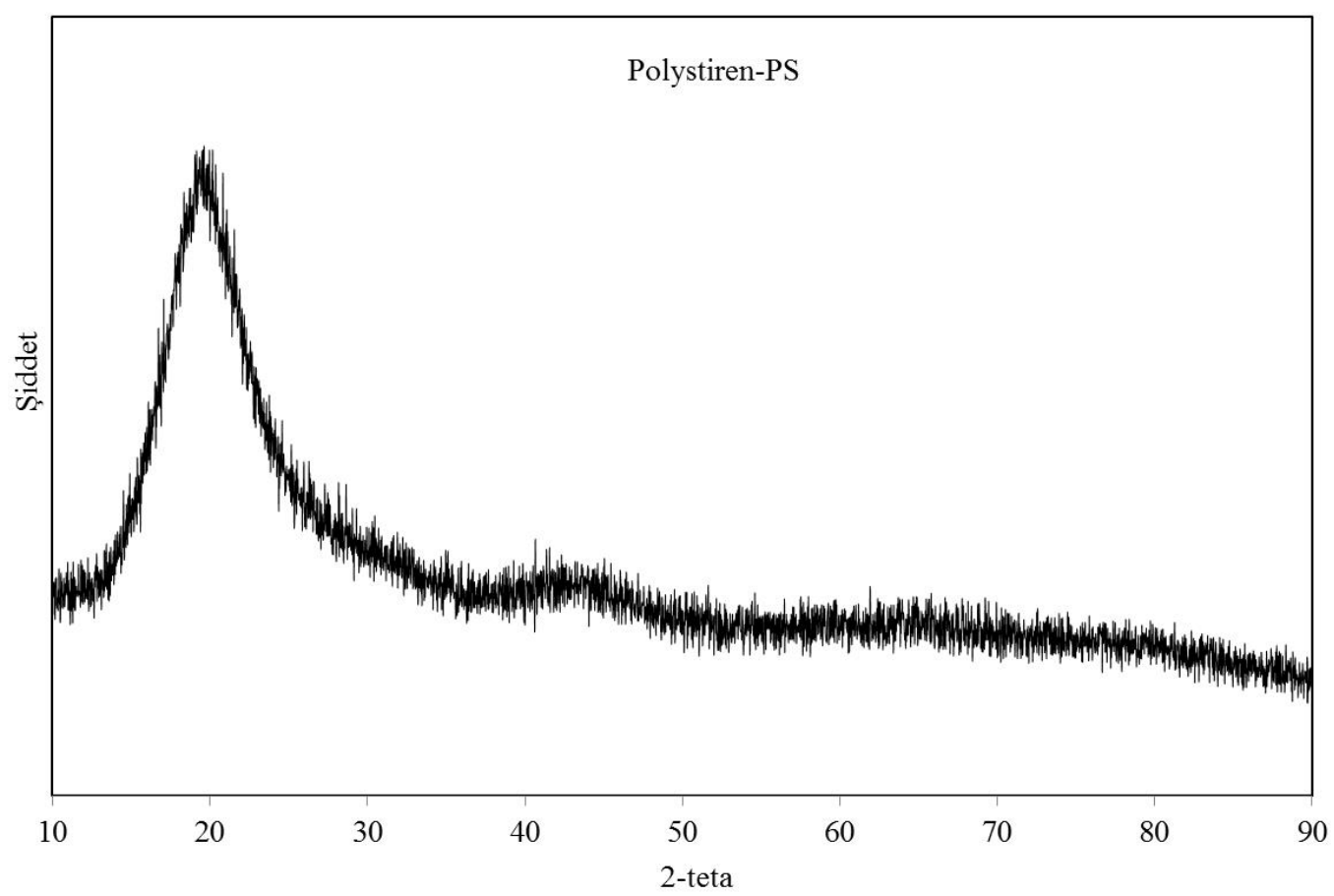

Şekil 6. PS şablonlarına ait X-Işını kırınım deseni (XRD pattern of PS templates) 


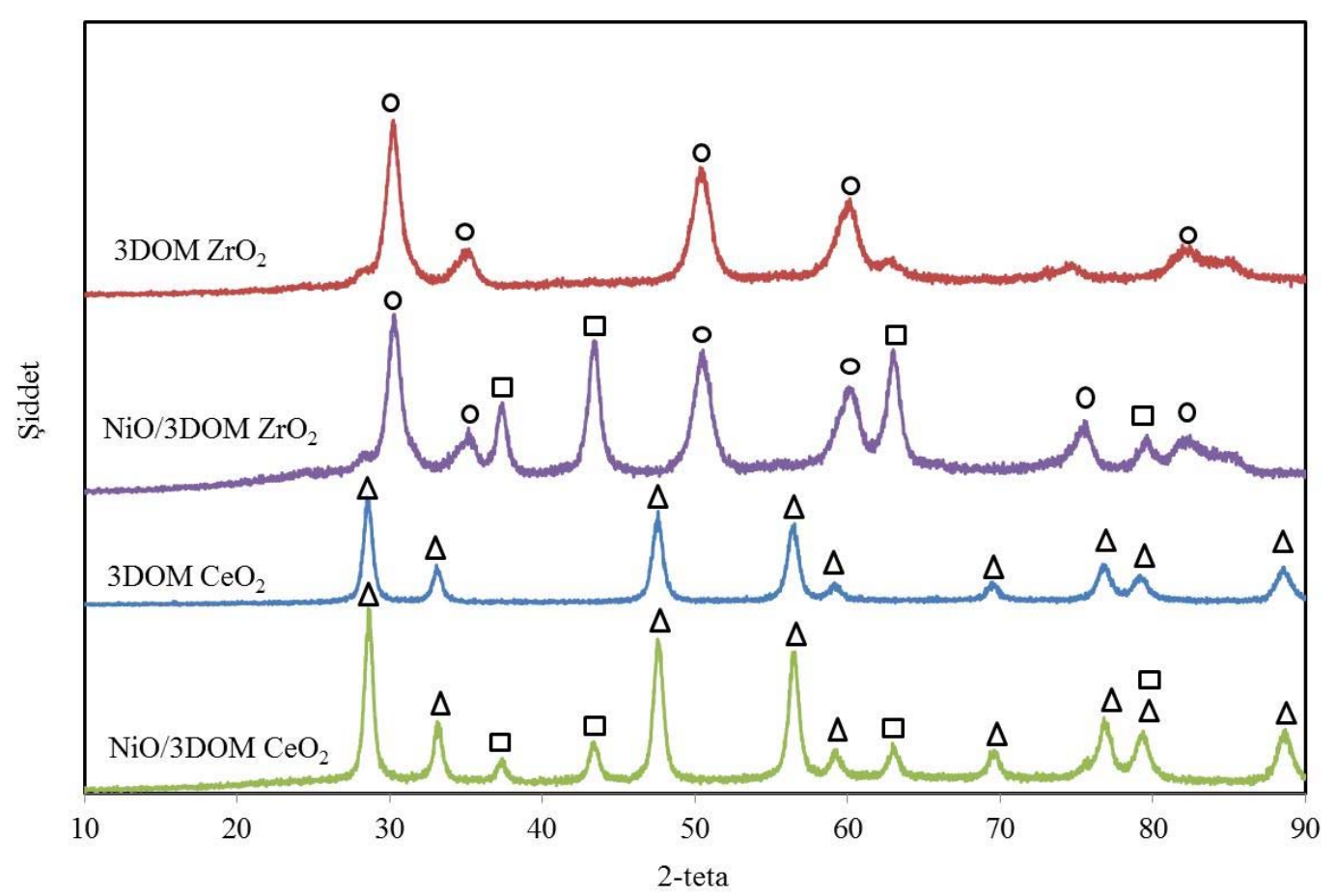

Şekil 7. 3DOM destek ve katalizörlere ait X-Işını kırınım desenleri (XRD patterns of $3 \mathrm{DOM}$ supports and catalysts) $\left(\Delta: \mathrm{CeO}_{2}, \mathbf{o}: \mathrm{ZrO}_{2}\right.$ and $\left.\square: \mathrm{NiO}\right)$

Tablo 2. Destek ve katalizörleri ortalama kristal boyutları (Average crystal size of the catalysts and supports).

\begin{tabular}{|c|c|c|c|}
\hline \multirow{2}{*}{ Katalizörler } & \multicolumn{3}{|c|}{ Ortalama Kristal Boyutu $(\AA)$} \\
\hline & $\mathrm{CeO}_{2}$ & $\mathrm{ZrO}_{2}$ & $\mathrm{NiO}$ \\
\hline $3 \mathrm{DOM} \mathrm{CeO}_{2}$ & 32 & & \\
\hline $\mathrm{NiO} / 3 \mathrm{DOM} \mathrm{CeO}_{2}$ & 23 & & 43 \\
\hline $3 \mathrm{DOM} \mathrm{ZrO}_{2}$ & & 25 & \\
\hline $\mathrm{NiO} / 3 \mathrm{DOM} \mathrm{ZrO}_{2}$ & & 21 & 24 \\
\hline
\end{tabular}

kalsinasyona bağlı olarak yapısında hiç monodispers PS şablonları kalmadığı görülmüş ve XRD diyagramlarının hiçbirinde $2 \theta=19,62^{\circ}$ ' de pik olmadığından da bu durum kanıtlanmıştır. $3 \mathrm{DOM} \mathrm{ZrO}_{2}$ 'de $2 \theta=30,217^{\circ}, 35^{\circ}, 50,217^{\circ}$, $60,217^{\circ}, 74,565^{\circ}, 82,173^{\circ}$ değerlerinde pikler elde edilmiştir. $\mathrm{ZrO}_{2}$ 'in kristal fazlarının çıkış açıları $2 \theta=30,2^{\circ}, 35^{\circ}, 50,2^{\circ}$, $60,2^{\circ}, 74,6^{\circ}, 82,2^{\circ}$ olarak belirlenmiştir. Li vd. [17], Gnanamoorthi vd. [18] ve Reyes-Acosta vd. [19] yaptıkları çalışmalarda $\mathrm{ZrO}_{2}$ kristal fazını çok yakın $2 \theta$ açıklarında elde etmişlerdir. $\mathrm{CeO}_{2}$ kristal fazı $2 \theta=28,7^{\circ}, 33^{\circ}, 47,2^{\circ}$, $56,2^{\circ}, 59,2^{\circ}, 69,2^{\circ}, 76,6^{\circ}, 79^{\circ}, 88,3^{\circ}$ kırılma açıklarında pikler vermiştir. Elde edilen bu kırılma açıları literatürde yer alan çalışmalar ile uyumludur. Parvulescu vd. [20], Nakagwa vd. [21] ve Yosefi vd. [22] yaptıkları çalışmalarda $\mathrm{CeO}_{2}$ fazına ait kırınım açılarının $2 \theta=60^{\circ}$ değerine kadar olanlarını çok yakın elde etmişlerdir. 50/50 mol. \% $\mathrm{NiO} / 3 \mathrm{DOM} \mathrm{CeO}$ katalizörüne ait XRD grafiğginde $\mathrm{CeO}_{2}$ ve $\mathrm{NiO}$ kristal fazlarından kaynaklanan difraksiyon pikleri elde edilmiştir. $\mathrm{CeO}_{2}$ kristal fazına ait difraksiyon pikleri $2 \theta=28,8^{\circ}, 33^{\circ}, 47,7^{\circ}, 56,8^{\circ}, 59,2^{\circ}, 69,7^{\circ}, 76,8^{\circ}, 79,4^{\circ}, 88,8^{\circ}$ kırınım açılarında elde edilirken $\mathrm{NiO}$ kristal fazına ait difraksiyon pikleri de $2 \theta=37,2^{\circ}, 43,4^{\circ}, 63^{\circ}, 76,8^{\circ}, 79,4^{\circ}$ kırınım açılarında elde edilmiştir. Qurashi vd. [23] yaptıkları çalışmada NiO kristal fazını çok yakın $2 \theta$ değerlerinde elde etmişler. 50/50 mol. \% NiO/3DOM CeO 2 katalizörü $\mathrm{ZrO}_{2}$ and $\mathrm{NiO}$ kristal fazlarından kaynaklanan difraksiyon pikleri göstermiștir. $2 \theta=30,4^{\circ}, 35,2^{\circ}, 50,4^{\circ}, 60^{\circ}, 75,6^{\circ}, 82,5^{\circ}$ kırınım açılarında elde edilen difraksiyon pikleri $\mathrm{ZrO}_{2}$ kristal fazından kaynaklanırken $2 \theta=37,5^{\circ}, 43,8^{\circ}, 63,1^{\circ}, 75,6^{\circ}, 79,6^{\circ}$ kırınım açılarında elde edilen difraksiyon pikleri NiO kristal fazından kaynaklanmaktadır. NiO kristal fazına ait kırınım açıları Gajengi vd. [24] ve Pascariu vd. [25] tarafindan yapılan çalışmalar ile uyumluluk göstermektedir.

X-Işını kırınım deseni analizleri kullanılarak 3DOM desteklerin ve katalizörlerin ortalama kristal boyutları hesaplanmıştır. Hesaplamada Eş. 3'de gösterilen DebyeScherrer denklemi kullanılmıştır.

$d=\frac{\mathrm{K} x \lambda}{\beta_{d} x \cos (\Theta)}$

Tablo 2'de destek ve katalizörlerde yer alan kristal fazlara ait ortlama kristal boyutları yer almaktadir. 3DOM $\mathrm{CeO}_{2}$ desteğinin yapısında $\mathrm{NiO}$ emdirildikten sonra $\mathrm{CeO}_{2}$ 'in ortlama kristal boyutunun $32 \AA$ 'dan $23 \AA$ değerine düştüğü 
ve 3DOM $\mathrm{ZrO}_{2}$ desteğinin yapısına $\mathrm{NiO}$ emdirildikten sonra $\mathrm{ZrO}_{2}$ 'in ortlama kristal boyutunun $25 \AA$ 'dan $21 \AA$ değerine düştüğü belirlenmiştir. Ayrıca $\mathrm{NiO} / 3 \mathrm{DOM} \quad \mathrm{CeO}_{2}$ katalizöründe yer alan $\mathrm{NiO}$ kristalinin ortalama kristal boyutunun $\mathrm{NiO} / 3 \mathrm{DOM} \mathrm{ZrO}_{2}$ katalizöründe yer alan $\mathrm{NiO}$ kristallerinin ortalama boyutunun yaklaşık 1,8 katıdır. Sonuç olarak $\mathrm{NiO} / 3 \mathrm{DOM} \mathrm{CeO}_{2}$ katalizöründe daha büyük $\mathrm{NiO}$ kristalleri oluşmuştur. Bu sonuç katalitik aktivite sonuçlarını etkilemiştir.

\subsection{3. $N_{2}$ Fizisorpsiyon analiz sonuçları}

( $N_{2}$ physisorption analysis results)

$\mathrm{N}_{2}$ fizisorpsiyon analizinden 3DOM desteklerin ve katalizörlerin adsorpsiyon/desorpsiyon izoterm tipleri, yüzey alan değerleri, ortalama gözenek çapları ve gözenek hacim değerleri belirlenmiştir (Şekil 8- 9; Tablo 3). 3DOM destekler ve katalizörler Tip II $\mathrm{N}_{2}$ adsorpsiyon-desorpsiyon izotermi ve $\mathrm{H} 3$ histerisis aralığı davranışı göstermişlerdir.

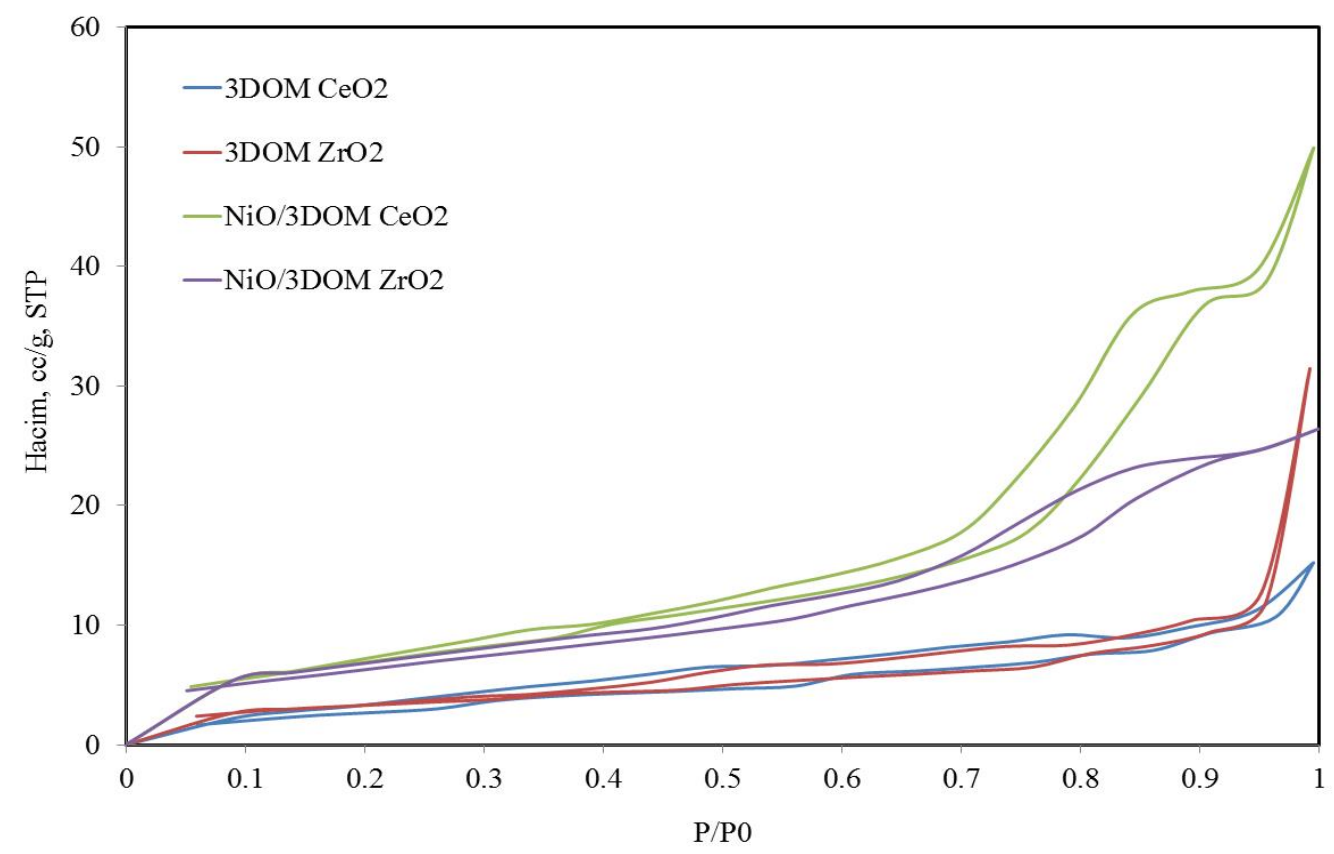

Şekil 8. 3DOM destek ve katalizörlere ait $\mathrm{N}_{2}$ adsorpsiyon/desorpsiyon izotermleri ( $\mathrm{N}_{2}$ adsorption/desorption isotherms of the 3DOM supports and catalysts)

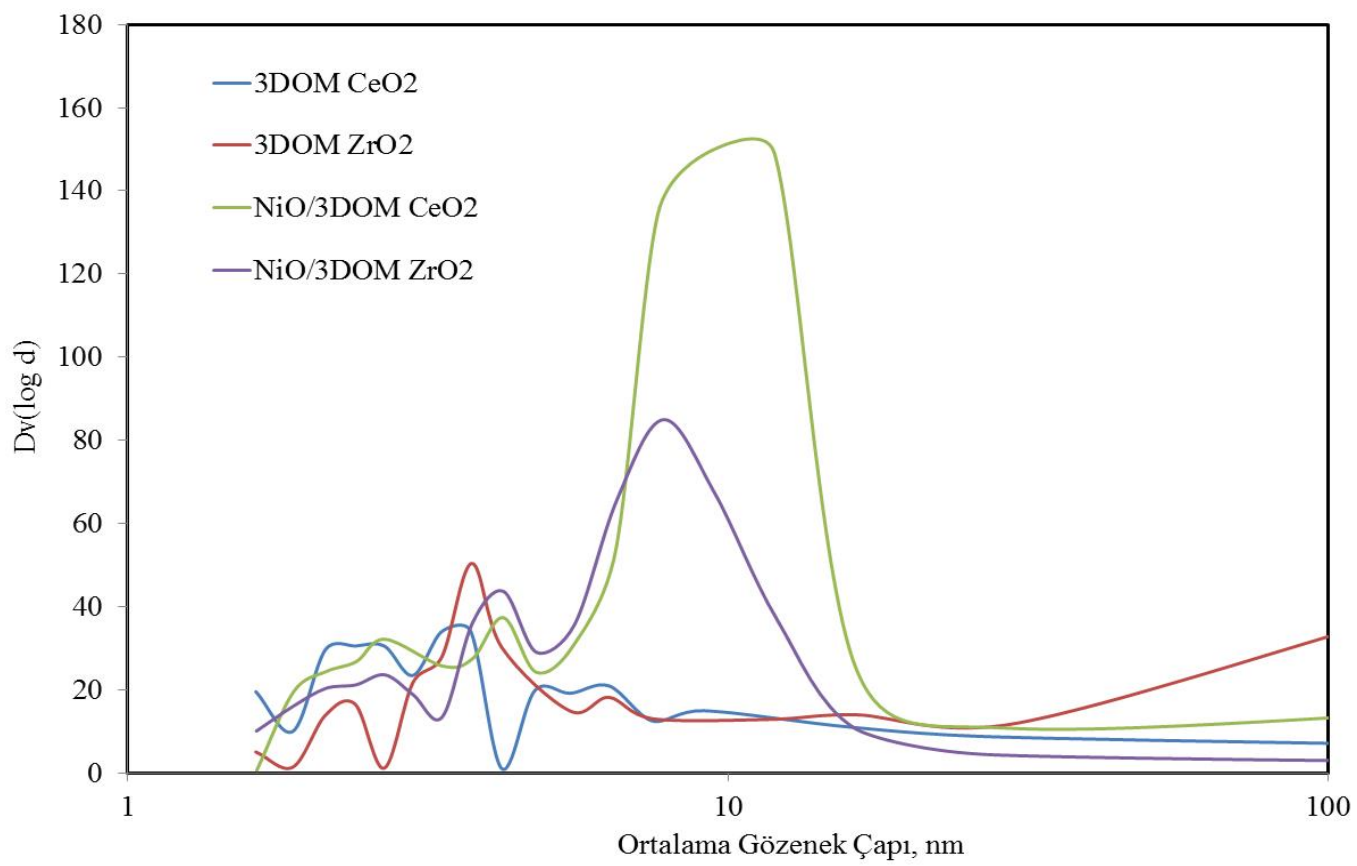

Şekil 9. 3DOM destek ve katalizörlere ait gözenek boyut dağılım grafiği (Pore size distribution of the 3DOM supports and catalysts) 
$3 \mathrm{DOM} \mathrm{CeO}_{2}, 3 \mathrm{DOM} \mathrm{ZrO}_{2}, 50 / 50 \mathrm{~mol}$ \% NiO/ $3 \mathrm{DOM} \mathrm{CeO}_{2}$ and 50/50 mol. \% NiO/3DOM $\mathrm{ZrO}_{2}$ destek ve katalizörlerin histerisis aralığ sirasıyla $0,1-0,98 \mathrm{P} / \mathrm{P}_{0}, 0,35-0,95 \mathrm{P} / \mathrm{P}_{0}, 0,2-$ $0,98 \mathrm{P} / \mathrm{P}_{0}$ ve $0,1-0,95 \mathrm{P} / \mathrm{P}_{0}$ değerleri arasına yerleşmiştir. İzotermlerin doğrusal orta bölümünde düşük basınçlı kısımda sınırlı olmayan tek tabaka-çok katmanlı adsorpsiyon gözlemlendiğinden numunenin gözeneksiz veya makrogözenekli bir adsorbent olduğu sonucu çıkarılmıştır. Bağıl basıncın artması yüzünden adsorpsiyonun artması, duvara kirlenmiş şekilde katılaşmış katı çözelti kümelerinin karakteristik özelliğidir. Yani, makrogözenekli duvar içinde çok sayıda mezo gözenekler bulunmaktadır. Zhang vd. [26]çalışmalarında da belirtildiği üzere makrogözenekler içinde yer alan mezogözenekler yüksek BET yüzey alanına katkıda bulunmaktadırlar. Yang vd. [27], Liu vd. [28] ve Li vd. [29] yaptıkları çalışmalarda Tip II $\mathrm{N}_{2}$ izotermi ile Tip H3 histerisis aralığ $\mathrm{CuO}-\mathrm{TiO}_{2}, \mathrm{MnO}_{\mathrm{x}} / 3 \mathrm{DOM} \mathrm{LaMnO}_{3}$ ve $\mathrm{Au} / 3 \mathrm{DOM} \mathrm{LaCoO}_{3}$ 3DOM yapılarında da elde edilmiştir. Tablo 3'de 3DOM desteklere ve katalizörlere ait mezogözenek çapları görülmektedir. Mezogözenekler makrogözenek duvarları içinde yer almaktadır.

\subsection{Aktivite Sonuçları (Activity Results)}

50/50 mol. \% NiO/3DOM $\mathrm{ZrO}_{2}$ ve 50/50 mol. \% $\mathrm{NiO}$ /3DOM $\mathrm{CeO}_{2}$ katalizörlerinin amonyak parçalanması reaksiyonunu için verdileri aktivite sonuçları Şekil 10'da verilmiştir. Reaksiyon çalışmalarında $50 \mathrm{ml} /$ dakika akış hızında saf amonyak kullanılmıştır. $500^{\circ} \mathrm{C}$ sıcaklığa kadar katalitik aktivitelerin ihmal edilecek düzeyde olduğu görülmektedir. $500^{\circ} \mathrm{C}$ sicaklıkta $50 / 50 \mathrm{~mol}$. \% NiO/3DOM $\mathrm{ZrO}_{2}$ ve 50/50 mol. \% NiO/3DOM $\mathrm{CeO}_{2}$ katalizörleri sırasıyla \%1,36 ve \%1,60 dönüşüm göstermiştir. Reaksiyon sıcaklığının yükselmesi katalizörlerin dönüşümünü arttırmıştır. $600^{\circ} \mathrm{C}$ sıcaklıkta 50/50 mol. \% NiO/3DOM ZrO için $\% 5,06$ ve $50 / 50$ mol. \% NiO/3DOM $\mathrm{CeO}_{2}$ için $\% 18,58$ dönüşüme ulaşılmıştır. 50/50 mol. \% NiO/3DOM $\mathrm{CeO}_{2}$ katalizöründen elde edilen dönüşüm 50/50 mol. $\%$ $\mathrm{NiO} / 3 \mathrm{DOM} \mathrm{ZrO}_{2}$ katalizöründen elde edilen dönüşüme göre daha fazladır. 50/50 mol. \% NiO/3 $\mathrm{DOM} \mathrm{CeO}_{2}$ katalizöründe aktivitenin daha iyi olmasının sebebi metalin daha iyi şekilde dağılmış olması ve yüzey alanının daha yüksek olmasına bağlanmaktadır. Aktivitenin yüksek olması yüklenen

Tablo 3. $\mathrm{N}_{2}$ fizisorpsiyon ölçümlerinden elde edilen destek ve katalizörlere ait fiziksel özellikler (Physical properties of the catalysts and supports obtained from $\mathrm{N}_{2}$ phsisorption measurement).

\begin{tabular}{|c|c|c|c|c|c|}
\hline Katalizörler & $\begin{array}{l}\text { Çoknoktalı } \\
\text { BET Yüzey } \\
\text { Alanı m²/g }\end{array}$ & $\begin{array}{l}\text { Ortalama } \\
\text { Mezogözenek } \\
\text { Çap1, nm }\end{array}$ & $\begin{array}{l}\text { Mikro+Mezo } \\
\text { Gözenek } \\
\text { Hacmi, cc/g } \\
\text { STP }\end{array}$ & $\begin{array}{l}\text { Toplam } \\
\text { Gözenek } \\
\text { Hacmi, } \\
\text { cc/g, STP }\end{array}$ & $\begin{array}{l}\text { \%Mikro+Mezo } \\
\text { Gözenek Hacmi }\end{array}$ \\
\hline $3 \mathrm{DOM}-\mathrm{CeO}_{2}$ & 10,7 & $\begin{array}{l}2,7,3,7,4,8,6,3 \\
9,1\end{array}$ & 12 & 15 & 80 \\
\hline $3 \mathrm{DOM}-\mathrm{ZrO}_{2}$ & 12,0 & $2,4,3,7,6,3,16,4$ & 17 & 31 & 55 \\
\hline $\mathrm{NiO} / 3 \mathrm{DOM}-\mathrm{CeO}_{2}$ & 26,1 & $2,7,4,2,12$ & 42 & 49 & 86 \\
\hline $\mathrm{NiO} / 3 \mathrm{DOM}-\mathrm{ZrO}_{2}$ & 23,4 & $2,7,4,2,7,8$ & 25 & 26 & 96 \\
\hline
\end{tabular}

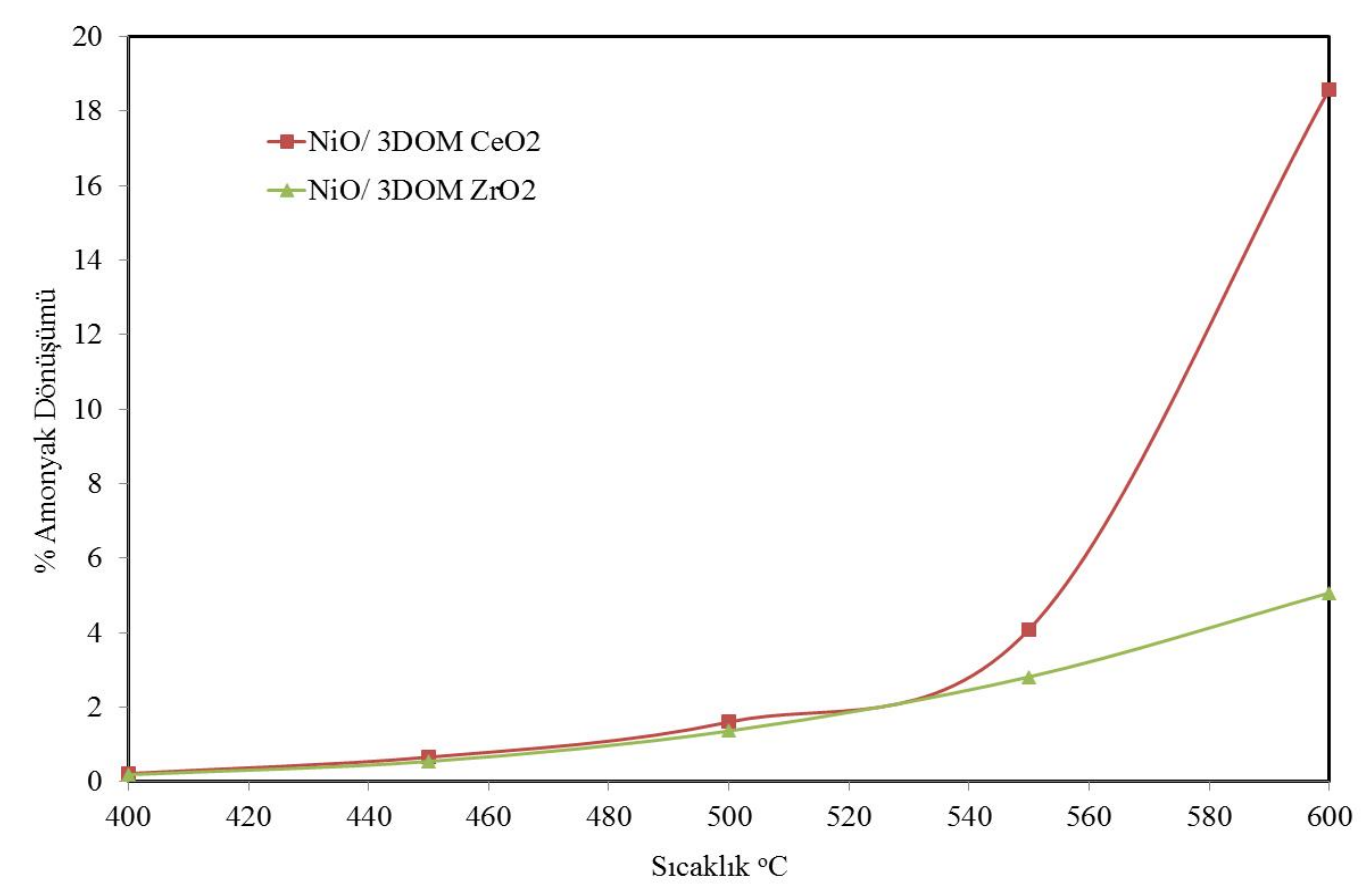

Şekil 10. Katalizörlerin $\mathrm{NH}_{3}$ 'den $\mathrm{H}_{2}$ üretim reaksiyonu için katalitik aktivite sonuçları (Catalytic activity results of the catalysts for the $\mathrm{H}_{2}$ production from $\mathrm{NH}_{3}$ ) 
metalin fazla miktarda olmasından daha çok metalin iyi şekilde dağılmasına bağlıdır. Elde edilen sonuçlarda dönüşümler yine de yüksek oranlarda değildir. Çünkü hazırlanan katalizörler makrogözeneklilik sınıfındandır. Amonyaklı hidrojen eldesi için genelde mezogözeneklilik sınıfına giren katalizörler tercih edildiği literatürden bilinmektedir. $\mathrm{Bu}$ çalışmadaki katalizörlerden elde edilen dönüşümlerin oranının düşük olması gözenek boyut yapısındaki farklılıklara bağlanabilir. Destek olarak kullanılan $3 \mathrm{DOM} \mathrm{CeO}$ ve $3 \mathrm{DOM} \mathrm{ZrO}_{2}$ üzerinden yapılan reaksiyon çalışmaları sonucunda bu malzemelerin amonyaktan hidrojen üretimi için hiç aktivite göstermedikleri tespit edilmiştir. Bu durumda yapıya nikel katılması aktiviteyi yükseltici etki yapmıştır. SEM-EDX sonuçları bize $50 / 50 \mathrm{~mol}$. \% NiO/3DOM $\mathrm{ZrO}_{2}$ katalizöründe yüklenen $\mathrm{NiO}$ molar oranının tasarlanan $\mathrm{NiO}$ molar oranından daha yüksek olduğunu ve X-Işını kırınım deseni analiz sonuçları da $\mathrm{NiO} / 3 \mathrm{DOM}_{\mathrm{ZrO}_{2}}$ katalizöründe yer alan $\mathrm{NiO}$ kristal fazının ortalama kristal boyutunun NiO/3DOM $\mathrm{CeO}_{2}$ katalizöründe yer alan $\mathrm{NiO}$ kristal fazınının ortalama kristal boyutundan daha küçük olduğunu göstermiştir. Yüksek nikeloksit molar oranı büyük nikeloksit partiküllerinin oluşumuna ve bu sonuçta düşük katalitik aktiviteye sebep olmuş olabilir. Bu sonuca bağlı olarak fazla $\mathrm{NiO}$ miktarı ve düşük $\mathrm{NiO}$ ortalama kristal boyutu $\mathrm{NiO} / 3 \mathrm{DOM} \mathrm{ZrO}_{2}$ katalizöründe negatif etki yapmıştır. $\mathrm{Bu}$ sonuç aynı zamanda aktivitenin ortalama kristal boyutu ile ters orantılı olduğunu da göstermiştir.

\section{SONUÇLAR (CONCLUSIONS)}

$\mathrm{Bu}$ çalışmada $3 \mathrm{DOM} \mathrm{ZrO}_{2}$ ve $3 \mathrm{DOM} \mathrm{CeO}_{2}$ destekli nikel içeren katalizörler sentezlenmiştir. Karakterizasyon

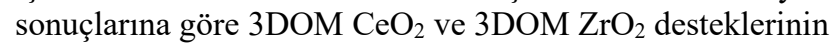
gözenek çap değerleri 204-321 nm değişmektedir ve NiO başarılı bir şekilde 3DOM yapısına eklenmiştir. $\mathrm{N}_{2}$ fizisorpsiyon analiz çalışmaları 3DOM desteklerin ve katalizörlerin makroduvarları içinde mezogözeneklerin olduğunu göstermiştir. Bu mezogözenekler yüksek BET yüzey alanı elde edilmesine neden olmuştur. Katalizörlerin katalitik aktiviteleri $400-600^{\circ} \mathrm{C}$ reaksiyon sıcaklıkları arasında amonyakdan hidrojen üretim reaksiyonu için belirlenmiştir. Katalizörlerde $500^{\circ} \mathrm{C}$ sıcaklığına kadar aktivite gözlenmezken sıcaklığın yükselmesi ile aktivite değerleride yükselmiştir. 50/50 mol. \% NiO/3DOM $\mathrm{ZrO}_{2}$ ve 50/50 mol. \% NiO/3DOM $\mathrm{CeO}_{2}$ katalizörlerinden sirasıyla $600^{\circ} \mathrm{C}$ reaksiyon sicaklığında $\% 5,6$ ve \%18,6 $\mathrm{NH}_{3}$ dönüşümleri elde edilmiştir.

\section{TEŞEKKÜRLER (ACKNOWLEDGEMENT)}

Gazi Üniversitesi Bilimsel Projeler Araştırma Birimi'ne çalışmamızı 18/2014-01 nolu proje ile desteklediği için ve Gaz Kromotograf sistemini tarafımıza sağladığı için Doç. Dr. Dilek VARIŞLI'ya teşekkürü bir borç biliriz.

\section{KAYNAKLAR (REFERENCES)}

1. Wei Y., Liu J., Zhao Z., Duan A., Jiang G., The catalysts of three-dimensionally ordered macroporous
$\mathrm{Ce}_{1 \_\mathrm{x}} \mathrm{Zr}_{\mathrm{x}} \mathrm{O}_{2}$-supported gold nanoparticles for soot combustion: The metal-support interaction, Journal of Catalysis, 287, 13-29, 2012.

2. Liu Y., Liu B., Wang Q., Li C., Hua W., Liu Y., Jing P., Zhao W., Zhang J., Three-dimensionally ordered macroporous $\mathrm{Au} / \mathrm{CeO}_{2}-\mathrm{Co}_{3} \mathrm{O}_{4}$ catalysts with mesoporous walls for enhanced $\mathrm{CO}$ preferential oxidation in $\mathrm{H}_{2}$-rich gases, Journal of Catalysis, 296, 65-76, 2012.

3. Xu J., Liu J., Zhao Z., Zheng J., Zhang G., Duan A., Jiang G., Three-dimensionally ordered macroporous $\mathrm{LaCo}_{\mathrm{x}} \mathrm{Fe}_{1-\mathrm{x}} \mathrm{O}_{3}$ perovskite-type complex oxide catalysts for diesel soot combustion, Catalysis Today, 153, 136142, 2010.

4. Wei Y., Liu J., Zhao Z., Xu C., Duan A., Jiang G., Structural and synergistic effects of three-dimensionally ordered macroporous $\mathrm{Ce}_{0.8} \mathrm{Zr}_{0.2} \mathrm{O}_{2}$-supported $\mathrm{Pt}$ nanoparticles on the catalytic performance for soot combustion, Applied Catalysis A- General, 453, 250261, 2013.

5. Han D., Li X., Zhang L., Wang Y., Yan Z., Liu S., Hierarchically ordered meso/macroporous $\gamma$-alumina for enhanced hydrodesulfurization performance, Microporous Mesoporous Materials, 158, 1-6, 2012.

6. Zhang J., Jin Y., Li C., Shen Y., Han L., Hu Z., Di X., Liu Z., Creation of three-dimensionally ordered macroporous $\mathrm{Au} / \mathrm{CeO}_{2}$ catalysts with controlled pore sizes and their enhanced catalytic performance for formaldehyde oxidation. Applied Catalysis. BEnvironmental, 91, 11-20, 2009.

7. Ji K., Dai H., Deng J., Song L., Gao B., Wang Y., Li X., Three-dimensionally ordered macroporous $\mathrm{Eu}_{0.6} \mathrm{Sr}_{0.4} \mathrm{FeO}_{3}$ supported cobalt oxides: Highly active nanocatalysts for the combustion of toluene, Applied Catalysis. B- Environmental 129, 539- 548, 2013.

8. Zhang X., Su H., Yang X., Catalytic performance of a three-dimensionally ordered macroporous $\mathrm{Co} / \mathrm{ZrO}_{2}$ catalyst in Fischer-Tropsch synthesis, Journal of Molecular Catalysis A- Chemcal, 360, 16-25, 2012.

9. Zhang H., Alhamed Y.A., Chu W., Ye Z., Al Zahrani A. Al, Petrova L., Controlling Co-support interaction in $\mathrm{Co} / \mathrm{MWCNTs}$ catalysts and catalytic performance for hydrogen production via $\mathrm{NH}_{3}$ decomposition, Applied Catalysis A- General, 464-465, 156-164, 2013.

10. Yao L.H., Li Y.X., Zhao J., Ji W.J., Au C.T., Core-shell structured nanoparticles $\left(\mathrm{M} @ \mathrm{SiO}_{2}, \mathrm{Al}_{2} \mathrm{O}_{3}, \mathrm{MgO} ; \mathrm{M}=\right.$ $\mathrm{Fe}, \mathrm{Co}, \mathrm{Ni}, \mathrm{Ru}$ ) and their application in COx-free $\mathrm{H}_{2}$ production via $\mathrm{NH}_{3}$ decomposition, Catalysis Today, 158, 401-408, 2010.

11. Lorenzut B., Montini T., Bevilacqua M., Fornasiero P., FeMo-based catalysts for $\mathrm{H}_{2}$ production by $\mathrm{NH}_{3}$ decomposition, Applied Catalysis B- Environmental, 125 (2012) 409-417, 2012.

12. Nakamura I., Fujitani T., Role of metal oxide supports in $\mathrm{NH}_{3}$ decomposition over $\mathrm{Ni}$ catalysts, Applied Catalysis A-General, 524, 45-49, 2016.

13. Liu B., Liu Y., Li C., Hu W., Jing P., Wang Q., Zhang J., Three-dimensionally ordered macroporous $\mathrm{Au} / \mathrm{CeO}_{2}-$ $\mathrm{Co}_{3} \mathrm{O}_{4}$ catalysts with nanoporous walls for enhanced 
catalytic oxidation of formaldehyde, Applied Catalysis. B- Environmental. 127, 47- 58, 2012.

14. Liu B., Li C., Zhang Y., Liu Y., Hu W., Wang Q., Han L., Zhang J., Investigation of catalytic mechanism of formaldehyde oxidation over three-dimensionally ordered macroporous $\mathrm{Au} / \mathrm{CeO}_{2}$ catalyst, Applied Catalysis. B- Environmental 111- 112, 467- 475, 2012.

15. Zhang Y., Liang H., Gao X.Y., Liu Y., Threedimensionally ordered macro-porous $\mathrm{CuO}-\mathrm{CeO}_{2}$ used for preferential oxidation of carbon monoxide in hydrogen-rich gases, Catalysis Communications, 10, 1432-1436, 2009.

16. Wang Z., Al-Daous M.A., Kiesel E.A., Li F., Stein A., Design and synthesis of $3 \mathrm{D}$ ordered macroporous $\mathrm{ZrO}_{2}$ /Zeolite nanocomposites, Microporous Mesoporous Materials, 120, 351-358, 2009.

17. Li S., Zheng J., Yang W., Zhao Y., A new synthesis process and characterization of three-dimensionally ordered macroporous $\mathrm{ZrO}_{2}$, Materials. Letters, 61, 4784-4786, 2007.

18. Gnanamoorthi K., Balakrishnan M., Mariappan R., Ranjith Kumar E., Effect of Ce doping on microstructural, morphological and optical properties of $\mathrm{ZrO}_{2}$ nanoparticles, Materials Science in Semiconductor Processing, 30, 518-526, 2015.

19. Reyes-Acosta M.A., Torres-Huerta A.M., DomínguezCrespo M.A., Flores-Vela A.I., Dorantes-Rosales H.J., Ramírez-Meneses E., Influence of $\mathrm{ZrO}_{2}$ nanoparticles and thermal treatment on the properties of PMMA/ZrO2 hybrid coatings, Journal of Alloys Compounds, 643, 150-158, 2014.

20. Parvulescu V.I., Tiseanu C., Local structure in $\mathrm{CeO}_{2}$ and $\mathrm{CeO}_{2}-\mathrm{ZrO}_{2}$ nanoparticles probed by Eu luminescence, Catalysis Today, 253, 33-39, 2015.

21. Nakagawa K., Ohshima T., Tezuka Y., Katayama M., Katoh M., Sugiyama S., Morphological effects of $\mathrm{CeO}_{2}$ nanostructures for catalytic soot combustion of $\mathrm{CuO} / \mathrm{CeO}_{2}$, Catalysis Today, 246, 67-71, 2015.

22. Yosefi L., Haghighi M., Allahyari S., Ashkriz S., Effect of ultrasound irradiation and Ni-loading on properties and performance of $\mathrm{CeO}_{2}$-doped $\mathrm{Ni} /$ clinoptilolite nanocatalyst used in polluted air treatment, Process Safety and Environmental Protection, 9, 26-37, 2015.

23. Qurashi A., Zhang Z., Asif M., Yamazaki T., Templateless surfactant-free hydrothermal synthesis $\mathrm{NiO}$ nanoflowers and their photoelectrochemical hydrogen production. International Journal of Hydrogen Energy, 40, 15801-15805, 2015.

24. Gajengi A.L., Sasaki T., Bhanage B.M., NiO nanoparticles catalyzed three component coupling reaction of aldehyde, amine and terminal alkynes, Catalysis Communications, 72, 174-179, 2015.

25. Pascariu P., Airinei A., Olaru N., Petrila I., Nica V., Sacarescu L., Tudorache F., Microstructure, electrical and humidity sensor properties of electrospun $\mathrm{NiO}-$ $\mathrm{SnO}_{2}$ nanofibers, Sensors and Actuators B, 222, 1024 1031, 2016.

26. Zhang G., Zhao Z., Xu J., Zheng J., Liu J., Jiang G., Duan A., He H., Comparative study on the preparation, characterization and catalytic performances of 3DOM Ce-based materials for the combustion of diesel soot, Applied Catalysis. B- Environmental, 107, 302- 315, 2011.

27. Yang R., Yang L., Tao T., Ma F., Xu M., Zhang Z., Contrastive study of structure and photocatalytic performance withthree-dimensionally ordered macroporous $\mathrm{CuO}-\mathrm{TiO}_{2}$ and $\mathrm{CuO} / \mathrm{TiO}_{2}$, Applied Surface Science, 288, 363- 368, 2014.

28. Liu Y., Dai H., Deng J., Du Y., Li X., Zhao Z., Wang Y., Gao B., Yang H., Guo G., In situ poly(methyl methacrylate)-templating generation and excellent catalytic performance of $\mathrm{MnOx} / 3 \mathrm{DOM} \mathrm{LaMnO}$ for the combustion of toluene and methanol, Applied Catalysis. B- Environmental, 140- 141, 493- 505, 2013.

29. Li X., Dai H., Deng J., Liu Y., Xie S., Zhao Z., Wang Y., Guo G., Arandiyan H., Au/3DOM $\mathrm{LaCoO}_{3}$ : Highperformance catalysts for the oxidation of carbon monoxide and toluene, Chemical Engineering Journal, 228, 965-975, 2013. 